\title{
NO PLIF Visualizations of the Orion Capsule in LENS-I
}

\author{
C. Combs ${ }^{1}$, N. Clemens ${ }^{2}$ \\ University of Texas, Austin TX, 78712 \\ P.M. Danehy ${ }^{3}$, B. Bathel ${ }^{4}$ \\ NASA Langley Research Center, Hampton, VA, 23681-2199 \\ R. Parker ${ }^{5}$, T. Wadhams ${ }^{6}$ and M. Holden ${ }^{7}$ \\ CUBRC, Buffalo, NY 14225 \\ and \\ B. Kirk $^{8}$ \\ NASA Johnson Space Center, Houston TX, 77058
}

\begin{abstract}
Planar laser-induced fluorescence (PLIF) of nitric oxide (NO) was used to visualize the interaction of reaction-control-system (RCS) jet flows in the wake of a hypersonic capsule reentry vehicle. The tests were performed at the Calspan University at Buffalo Research Center's (CUBRC) LENS-I reflected shock tunnel facility. This was the first application of PLIF to study RCS jets in a large-scale pulsed hypersonic facility. The LENS-I facility allowed RCS jet flows to be studied while varying the flow enthalpy, Reynolds number, angle of attack and jet configuration. The interaction of pitch and roll jets with the flowfield was investigated. Additionally, thin film sensors were used to monitor heat transfer on the surface of the model to detect any localized heating resulting from the firing of the RCS jets. Tests were conducted with the model held at angles of attack of $18^{\circ}$ and $22^{\circ}$. The nominal Mach number in all tests was 8 , while Reynolds number based on model diameter ranged from $2.2 \times 10^{6}-1.5 \times 10^{7}$. Images were processed using the Virtual Diagnostics Interface (ViDI) system developed at NASA Langley Research Center to provide a three-dimensional display of the experimental data.
\end{abstract}

$\begin{array}{ll}\mathrm{CFD} & =\text { Computational Fluid Dynamics } \\ \mathrm{CO}_{2} & =\text { Carbon Dioxide } \\ \mathrm{FOV} & =\text { Field of View } \\ \mathrm{H}_{2} & =\text { Hydrogen } \\ \mathrm{He} & =\text { Helium } \\ \mathrm{ISS} & =\text { International Space Station } \\ \mathrm{MPCV} & =\text { Multi-Purpose Crew Vehicle } \\ \mathrm{N}_{2} & =\text { Nitrogen } \\ \mathrm{N}_{2} \mathrm{H}_{4} & =\text { Hydrazine } \\ \mathrm{NO} & =\text { Nitric Oxide } \\ \mathrm{PIV} & =\text { Particle Image Velocimetry } \\ \text { PLIF } & =\text { Planar Laser-Induced Fluorescence }\end{array}$

${ }^{1}$ Graduate Student, Department of Aerospace Engineering \& Engineering Mechanics, Member AIAA.

${ }^{2}$ Bob R. Dorsey Professor in Engineering, Department of Aerospace Engineering \& Engineering Mechanics, Member AIAA.

${ }^{3}$ Research Scientist, Advanced Sensing and Optical Measurement Branch, MS 493, Associate Fellow AIAA.

${ }^{4}$ Graduate Student, University of Virginia and NASA Graduate Co-op, Hampton, Virginia, AIAA Student Member.

${ }^{5}$ Senior Research Scientist, Member AIAA

${ }^{6}$ Senior Research Scientist, Senior Member AIAA

${ }^{7}$ Program Manager, Fellow AIAA

${ }^{8}$ Research Scientist, Member AIAA 


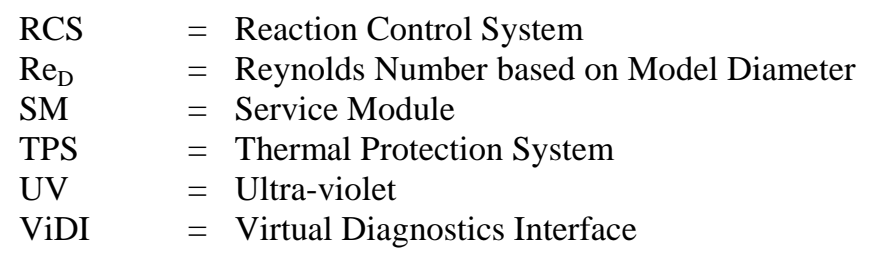

\section{Introduction}

Beginning with United States' Project Mercury and Russia's Vostok Programme, capsule-shaped reentry vehicles have been a fixture in manned spaceflight programs around the world. ${ }^{1}$ With NASA's selection of a capsule design to be the successor to the space shuttle program, there has been a renewed interest in this type of reentry vehicle in recent years. There are many advantages to a blunt-body capsule configuration over other vehicle shapes including light weight, simpler and safer launch vehicle integration, and an aerodynamic design with which researchers and engineers have substantial experience. ${ }^{2}$ NASA's choice to succeed the space shuttle, the Orion Multi-Purpose Crew Vehicle (MPCV), will carry crew to and from space and has been designed to carry a crew of four on lunar missions and accommodate six crew members for International Space Station (ISS) and future Mars mission scenarios. ${ }^{2}$

Reaction Control System (RCS) jets provide capsule vehicles with steering capability both on-orbit and during planetary entry through yaw, pitch, and roll control. The MPCV will be equipped with an RCS composed of twelve hydrazine $\left(\mathrm{N}_{2} \mathrm{H}_{4}\right)$ thrusters to provide vehicle attitude control from Service Module (SM) separation through atmospheric reentry. ${ }^{3}$ These engines will each provide $445 \mathrm{~N}(100 \mathrm{lbf})$ of thrust in the pitch, roll, and yaw directions. ${ }^{2}$ There will be two thrusters in each of the six directions (+/- pitch, $+/$ - roll, $+/$ - yaw). ${ }^{2}$ The configuration of these thrusters is similar to that of the Apollo RCS system ${ }^{4}$ and can be seen in the figure below. The design of the converging/diverging nozzle uses a 40:1 expansion ratio, resulting in a nominal Mach number of 5.6 (assuming $\gamma=$ 1.4).2 With a chamber pressure of 300 psia and an oxidizer to fuel mixture ratio of 1.4:1 by mass, the specific impulse for the RCS system is $274 \mathrm{sec}^{2}$ Tank pressure for the primary RCS is regulated using a high-pressure gaseous Helium pressurization system. ${ }^{2}$ During atmospheric flight, the RCS provides roll torque to control the direction of the MPCV lift vector and to counteract induced spin torques and provides dampening of induced pitch and yaw instabilities. ${ }^{2,5}$ These thrusters will produce under-expanded jets of exhaust and the effect of the interaction of these jets with the capsule's gas-dynamic environment must be understood. First, the effect of the jets on the flowfield around the capsule must be investigated to determine if sufficient interference exists to alter the net force applied by the RCS jets to the vehicle. ${ }^{6,7}$ Additionally, the jets can cause localized heating on the capsule, ${ }^{8,9}$ influencing the sizing and design of the Thermal Protection System (TPS). Currently, there is a limited amount of relevant capsule afterbody re-entry heating data. ${ }^{10-14}$ It is important to collect experimental data on complex flowfields such as this one to help validate computational fluid dynamics (CFD) models. ${ }^{15,16}$ 


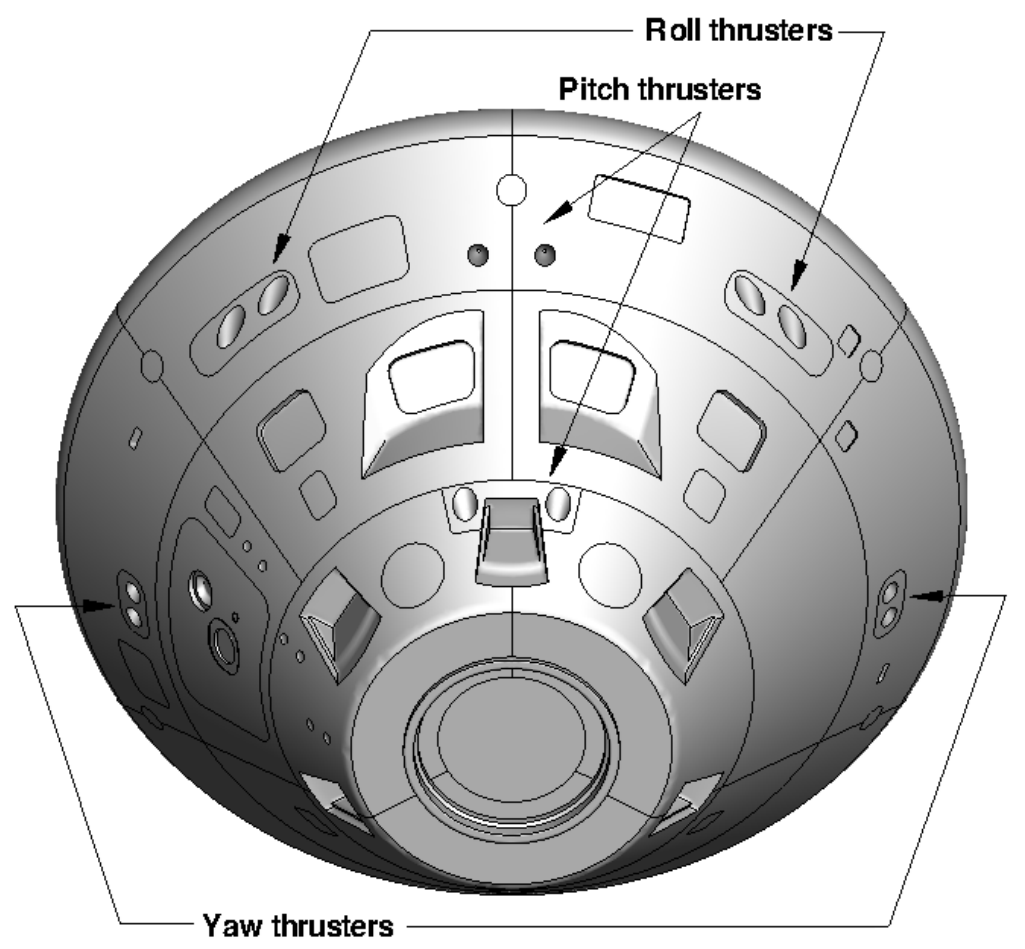

Figure 1: Layout of the MPCV RCS.3

Off-body non-intrusive flow visualization of the RCS jets at near-flight conditions is crucial to understand the interaction of these jets with the surrounding flowfield. In this paper, we used planar laser-induced fluorescence (PLIF) of nitric oxide (NO) to visualize pitch and roll RCS jets on a model of the MPCV. PLIF is a flow diagnostic technique that can be used to gather qualitative or quantitative information about a two-dimensional slice of a flow. With this method, a thin laser sheet is passed through the flow, exciting the species of interest. The excited species will then emit a photon which can then be recorded by a camera. The PLIF signal provides a qualitative measure of the scalar (in this case NO) in the flow field. PLIF has previously been used by NASA researchers to visualize capsule RCS jets, ${ }^{17}$ simulated heat shield ablation, ${ }^{18}$ flow over flat plates and cavities, ${ }^{19}$ and various other geometries. Additionally, a high-speed $(\sim 100 \mathrm{kHz}-1 \mathrm{MHz})$ NO PLIF system has previously been used to study a non-reacting supersonic combustor cavity in Calspan University at Buffalo Research Center's (CUBRC) 48" shock tunnel, ${ }^{20}$ but this is the first application of PLIF to study RCS jets in a large-scale pulsed hypersonic facility. The LENS-I facility allowed RCS jet flows to be studied while varying the flow enthalpy. NO PLIF has previously been used in high-enthalpy shock tunnel facilities at numerous laboratories, though RCS jet flows have not been investigated in these facilities to our knowledge. ${ }^{21-24}$

The laser system used in the current work operates at $10 \mathrm{~Hz}$ allowing only one image per tunnel run. However, the current system produces pulses with 10x higher laser energy than the high speed system previously used at CUBRC, allowing larger (6"x6") field of view (FOV) images to be captured with a good signal-to-noise ratio. NO PLIF flow visualization was selected for a variety of reasons. Commonly used flow visualization techniques such as schlieren $^{25}$ and Rayleigh scattering ${ }^{26}$ would produce poor-quality images in the low pressure, low density region of the vehicle's wake region. Particle Image Velocimetry (PIV) is another option, but the particles could be difficult to seed, could interfere with or not follow the flowfield and perhaps could clog the RCS jet nozzles. Additionally, NO can be mixed with a molecular nitrogen $\left(\mathrm{N}_{2}\right)$ jet gas simulant and seeded directly into the flow through the RCS jet nozzles. With this technique, heavy particle/molecule velocity slip or lag is of no concern because the molecular weight of $\mathrm{NO}(30 \mathrm{~g} / \mathrm{mol})$ is nearly the same as $\mathrm{N}_{2}(28 \mathrm{~g} / \mathrm{mol})$.

To complement the off-body flow visualization, a network of thin-film sensors was used to measure heat transfer rates on the model's heat shield and afterbody to provide insight into any localized heating resulting from the RCS jets. 


\section{Experimental Description}

The experiment was performed in the LENS-I reflected shock tunnel facility at CUBRC. The test apparatus consisted of three main components: the test model, the wind tunnel facility and the optical visualization systems, which are detailed below. The analysis involved image processing and rendering in a three-dimensional software environment. These are summarized briefly in this section with references describing where more details can be found.

\section{A. Model Geometry}

Diameter $1=4.1 "$, Diameter $2=10 ”$, Length $=6.566 "$, Angle $=29.995 \mathrm{deg}$

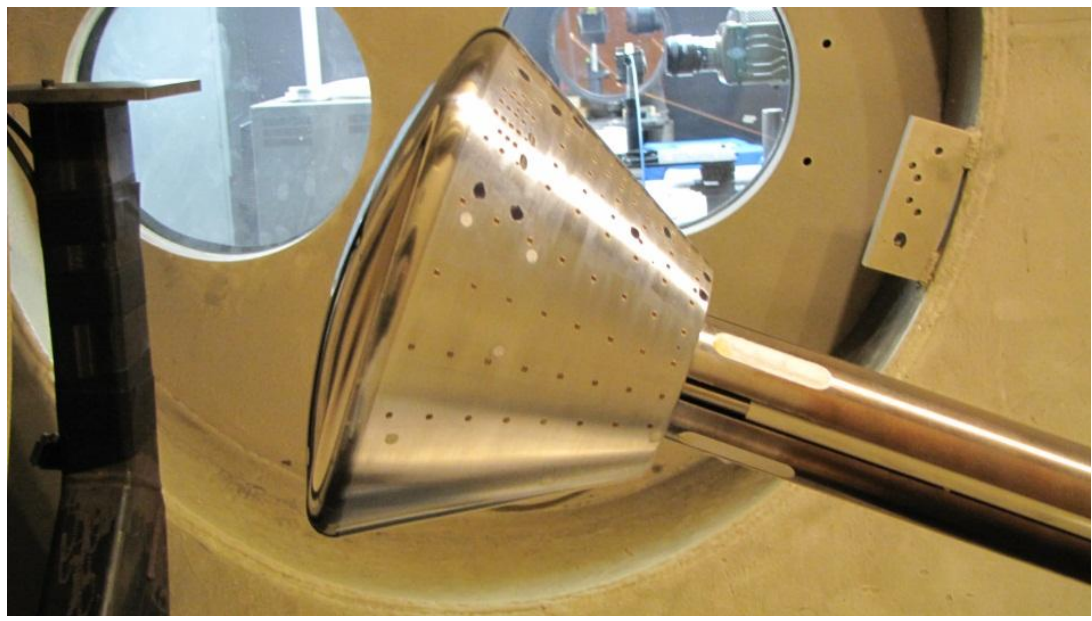

Figure 2: Photograph of the capsule model installed in the test section of the LENS-I reflected shock tunnel.
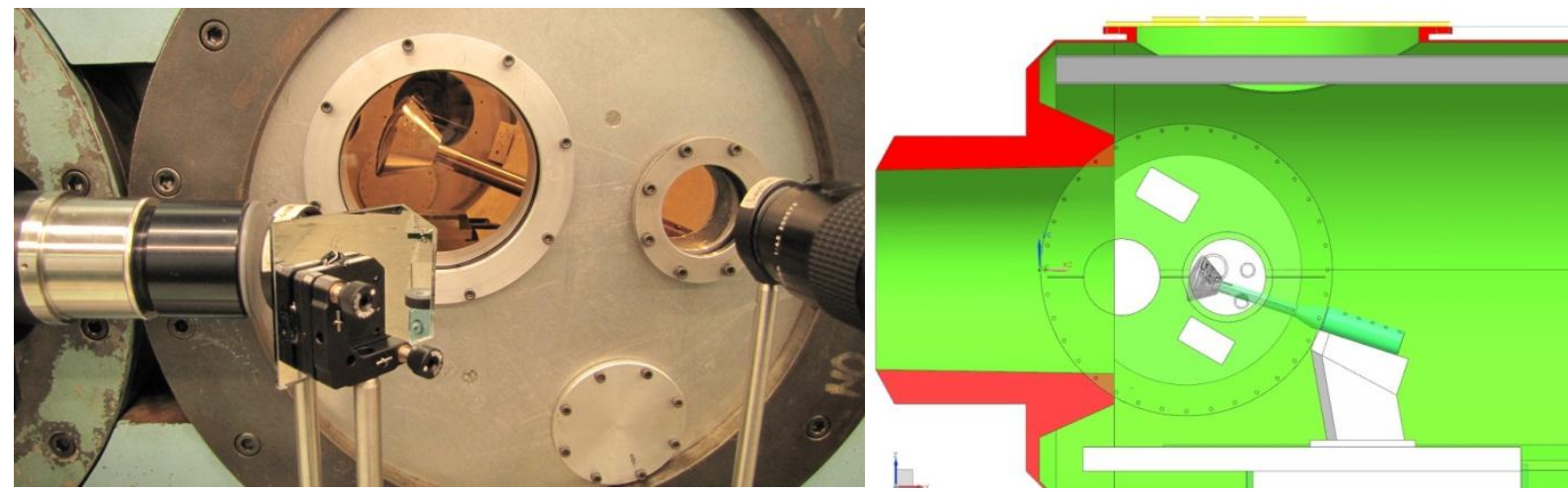

Figure 3: Photograph (left) and schematic (right) of the capsule model installed in the test section of the LENS-I reflected shock tunnel.

\section{B. Wind Tunnel, Operating Conditions, Mass Flow Control and Data Acquisition Systems}

The LENS-I facility is a large shock tunnel with an electrically heated driver section located at CUBRC in Buffalo, New York, USA. Reference 27 details this facility, a summary of which is provided here. LENS-I was designed to be used for high-altitude, high Mach number testing. ${ }^{27}$ Reynolds numbers ranging from $1.0 \times 10^{4}-1.0$ x $10^{8} \mathrm{ft}^{-1}$ can be achieved in this facility, with test times lasting up to $25 \mathrm{~ms}{ }^{27}$ Free stream Reynolds number based on model diameter was $2.2 \times 10^{6}$ for this experimental program. For the driven, or test gas, $\mathrm{N}_{2}$, Air and mixtures of $\mathrm{N}_{2}$ and $\mathrm{O}_{2}$ were used as indicated in the test matrix shown in Table 1. A nozzle with a nominal Mach number of 8 was used for all tests discussed herein. The nozzle had an exit diameter of $1.22 \mathrm{~m}\left(48^{\prime \prime}\right)$. In the cases where the interaction of the RCS jets with the flowfield was imaged using NO PLIF, a gas mixture composed of 1\% NO, $49 \%$ $\mathrm{N}_{2}$, and $50 \% \mathrm{H}_{2}$ was seeded into the flow through the RCS nozzle(s) of interest using a pressurized plenum. For the external-seeding method, a $3.2 \mathrm{~mm}$ (1/8 in) outer diameter tube was attached parallel to the sting to supply NO gas 
to a $7.7 \mathrm{~mm}(0.3 \mathrm{in})$ diameter and $7.7 \mathrm{~mm}(0.3 \mathrm{in})$ length porous metal cylinder attached to the end of the tube using a high-temperature epoxy.

\begin{tabular}{|c|c|c|c|c|c|c|c|}
\hline $\begin{array}{c}\text { Run } \\
\text { Number }\end{array}$ & $\begin{array}{c}\text { Test } \\
\text { Date }\end{array}$ & $\begin{array}{c}\text { Mach } \\
\text { Number }\end{array}$ & $\begin{array}{c}\text { Reynolds } \\
\text { Number } \\
\left(\mathbf{R e}_{\mathrm{D}} \mathbf{)}\right.\end{array}$ & $\begin{array}{c}\text { Test } \\
\text { Gas }\end{array}$ & $\begin{array}{c}\text { Angle of } \\
\text { Attack } \\
\text { (degrees) }\end{array}$ & $\begin{array}{c}\text { Active RCS Jet } \\
(\mathbf{1} \text { or } \mathbf{2})\end{array}$ & RCS Gas \\
\hline 1 & $5 / 31 / 12$ & 8.0 & $8.00 \times 10^{6}$ & Nitrogen & 18 & None & None \\
\hline 2 & $6 / 5 / 12$ & 8.0 & $4.00 \times 10^{6}$ & Nitrogen & 18 & None & None \\
\hline 3 & $6 / 6 / 12$ & 8.0 & $6.00 \times 10^{6}$ & Nitrogen & 18 & None & None \\
\hline 4 & $6 / 7 / 12$ & 8.0 & $2.20 \times 10^{6}$ & Nitrogen & 18 & None & None \\
\hline 9 & $6 / 20 / 12$ & 8.0 & $2.20 \times 10^{6}$ & Nitrogen & 18 & Roll (2) & Hydrogen/Nitrogen/1\%NO \\
\hline 10 & $6 / 21 / 12$ & 8.0 & $2.20 \times 10^{6}$ & Nitrogen & 18 & Roll (2) & Hydrogen/Nitrogen/1\%NO \\
\hline 12 & $7 / 3 / 12$ & 8.0 & $2.20 \times 10^{6}$ & Nitrogen & 18 & Roll (2) & Hydrogen/Nitrogen/1\%NO \\
\hline 13 & $7 / 5 / 12$ & 8.0 & $2.20 \times 10^{6}$ & Nitrogen & 18 & Pitch Down (1) & Hydrogen/Nitrogen/1\%NO \\
\hline 15 & $7 / 27 / 12$ & 8.0 & $2.20 \times 10^{6}$ & Nitrogen & 22 & Roll (2)/PD (1) & Hydrogen/Nitrogen/1\%NO \\
\hline 20 & $7 / 31 / 12$ & 8.0 & $2.20 \times 10^{6}$ & Nitrogen & 22 & Roll (1) & Hydrogen/Nitrogen/1\%NO \\
\hline 21 & $7 / 31 / 12$ & 8.0 & $2.20 \times 10^{6}$ & Nitrogen & 22 & Pitch Down $(2)$ & Hydrogen/Nitrogen/1\%NO \\
\hline 22 & $8 / 1 / 12$ & 8.0 & $2.20 \times 10^{6}$ & Nitrogen & 18 & Pitch Down $(2)$ & Hydrogen/Nitrogen/1\%NO \\
\hline 23 & $9 / 10 / 12$ & 8.0 & $2.20 \times 10^{6}$ & Nitrogen & 18 & Roll (2) & Hydrogen/Nitrogen/1\%NO \\
\hline 24 & $9 / 11 / 12$ & 8.0 & $2.20 \times 10^{6}$ & Nitrogen & 18 & None & None \\
\hline 25 & $9 / 13 / 12$ & 8.0 & $2.20 \times 10^{6}$ & Air & 22 & None & None \\
\hline 26 & $9 / 17 / 12$ & 8.0 & $2.20 \times 10^{6}$ & Nitrogen & 18 & None & None \\
\hline 27 & $9 / 17 / 12$ & 8.0 & $1.50 \times 10^{7}$ & Nitrogen & 18 & None & None \\
\hline 28 & $9 / 18 / 12$ & 8.0 & $2.20 \times 10^{6}$ & Nitrogen & 18 & None & None \\
\hline & & & & & & & \\
\hline
\end{tabular}

Table 1: Test matrix used for the experimental program presented herein.

\section{Planar laser-induced fluorescence (PLIF) Imaging System}

NO PLIF uses an ultraviolet laser sheet to interrogate a slice in the flow containing seeded NO. This UV light excites fluorescence from the NO molecules, which is detected by a high-speed digital camera. Details of the measurement system used in this experiment, as well as the experimental procedure used, can be found in References 28, 29 and 30. One of NASA's two mobile PLIF systems was shipped to CUBRC and installed next to the LENS-I facility. The laser system uses an injection seeded Nd:YAG laser to pump a Sirah Cobra Stretch dye laser and Sirah Frequency Conversion Unit (FCU). The dye laser was operated near $624 \mathrm{~nm}$ and was sum-frequency mixed with the third harmonic of the Nd:YAG laser to produce the UV light used to excite NO. The resulting laser output, at $226.25 \mathrm{~nm}$, was tuned to excite the strongly fluorescing spectral lines of NO near the $\mathrm{Q}_{1}$ branch band head (where $\mathrm{Q}$ denotes a change in rotational quantum number equal to zero). During initial high $(3 \mathrm{MJ} / \mathrm{kg}$ ) enthalpy runs using air as the test gas, no fluorescence was observed. Calculations indicated that the high concentration of NO gas in the flow absorbed $99.9 \%$ of the laser light before it reached the camera's FOV near the model. For subsequent high enthalpy runs, the test gas was switched to a $99.5 \% \mathrm{~N} 2,0.5 \% \mathrm{O} 2$ mixture resulting in $\sim 1 \% \mathrm{NO}$ in the faciltity freestream. Furthermore, the laser was tuned to 226.14 to excite a weaker, less populated $\mathrm{R}_{2}(13.5)$ line of NO. This method reduced the laser absorption so that only half the laser light was still available to produce fluorescence when the laser entered the camera FOV. These changes produced adequate signal levels.

To reach the model, the UV laser beam passed up to the top of the facility where it was formed into a laser sheet using a $36 \mathrm{~mm}$ focal length cylindrical lens followed by a $2000 \mathrm{~mm}$ focal length, $100 \mathrm{~mm}$ diameter spherical lens which was nearly 2 meters from the capsule model installed in the wind tunnel. The distance between the two lenses was adjusted so that the laser sheet would expand to a width of about $150 \mathrm{~mm}$ inside the test section. The resulting laser sheet was about $1 \mathrm{~mm}$ thick (FWHM) in the measurement region. The same cameras, excitation schemes, etc., were used as in past work including high-efficiency filters (Layertec GmbH, Germany, <1\% transmission at $226 \mathrm{~nm}$ and $>80 \%$ transmission at $235-280 \mathrm{~nm}$ ) were used to transmit the LIF signal while rejecting the laser scatter. For the high-enthalpy runs, UV-5 filters were placed in front of the camera lenses to attenuate natural luminosity from the flow. The fluorescence was imaged onto a gated, intensified CCD at a viewing angle normal to the laser sheet. Images were acquired using $100 \mathrm{~mm}$ focal length lenses. The camera magnifications were measured from images 
acquired of a regular pattern of dots of known spacing (known as a dotcard), with this dotcard placed in the image plane. The camera FOV was about $200 \mathrm{~mm}$. The images can be obtained at a rate of $10 \mathrm{~Hz}$ with flow-stopping time resolution $(<1$ microsecond). A timing circuit was developed to synchronize the Nd:YAG laser operation with the pulsed facility.

\section{PLIF Flow Visualization Image Processing}

Single-shot PLIF images were processed using smoothing routines and by adding false color tables. Images were corrected for spatial variations in laser sheet intensity, but neither the laser-sheet intensity nor spatial distribution was measured on a shot-to-shot basis. Rather, the average laser sheet spatial intensity variation has been measured by injecting NO into a near vacuum, resulting in uniform NO seeding, after the tunnel runs and acquiring an average of approximately 100 PLIF images. Single-shot images were divided by this laser-sheet intensity profile. The images were corrected for perspective and lens distortions. The images were then made into bitmap images or movies for display on the model using ViDI technology as described below. Additional details describing the image processing method for smoothing, thresholding the images, and for removal of lens and perspective distortion can be found in Reference 31.

\section{E. Virtual Diagnostics Interface (ViDI)}

The Virtual Diagnostics Interface (ViDI) ${ }^{32}$ is a software tool, developed at NASA Langley Research Center that provides unified data handling and interactive three-dimensional display of experimental data and computational predictions. It is a combination of custom-developed software applications and Autodesk® $3 \mathrm{ds}$ Max ${ }^{\circledR}$, a commercially available, CAD-like software package for three-dimensional rendering and animation. ${ }^{33}$ ViDI technology can be applied to three main areas: 1) pre-test planning and optimization; 2) visualization and analysis of experimental data and/or computational predictions; and 3) establishment of a central hub to visualize, store and retrieve experimental results. For this experiment, ViDI was used primarily for post-test visualization of the PLIF data as in Reference 31.

\section{Experimental Results and Discussion}

\section{A. Wind-off Measurements}

So called "wind off" measurements were obtained in the test section of the CUBRC LENS-I facility with the facility acting only as a static vacuum chamber, allowing alignment and testing of the measurement system while also allowing the characteristics of the RCS jets to be studied in the absence of tunnel flow. Figure 4 is a ViDI rendering of the capsule geometry with a simulated laser sheet impinging on the model. This figure depicts the location of the laser sheet for all tunnel runs, with the exception of one run where the laser sheet was aligned with the roll jet nearest to the centerline of the model. Note that the laser sheet is aligned with the center of the pitch down RCS jet and is parallel to the free-stream flow but not aligned with the centerline of the model. 


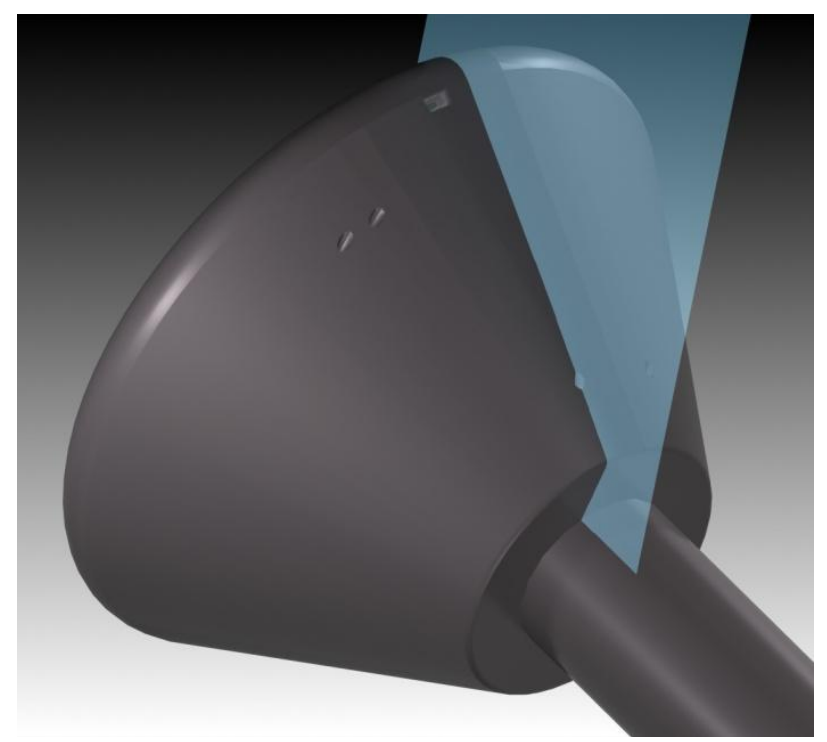

Figure 4: ViDI rendering of the capsule model with simulated laser sheet.

Figure 5 shows a series of images obtained while manually scanning the laser sheet spatially through the pitch down RCS jet. The jet had a constant pressure of 350 psia and exited to a chamber pressure of 0.77 psia. Performing a spatial scan on the jet provides an opportunity to study structures at different planes in the jet, something that would not be possible with other common flow visualization techniques such as shadowgraph or schlieren. The laser sheet is oriented vertically in the tunnel. The RCS jet is at a slight angle to the laser sheet so the resulting images are not obtained on an axis of symmetry; rather the visualization depicts an oblique slice through a classic underexpanded jet. The barrel shocks and Mach disk can be seen, particularly in images 7-15. A reflection of the PLIF signal from the capsule model can be seen to the left of the jet, for example in images 11-22. 


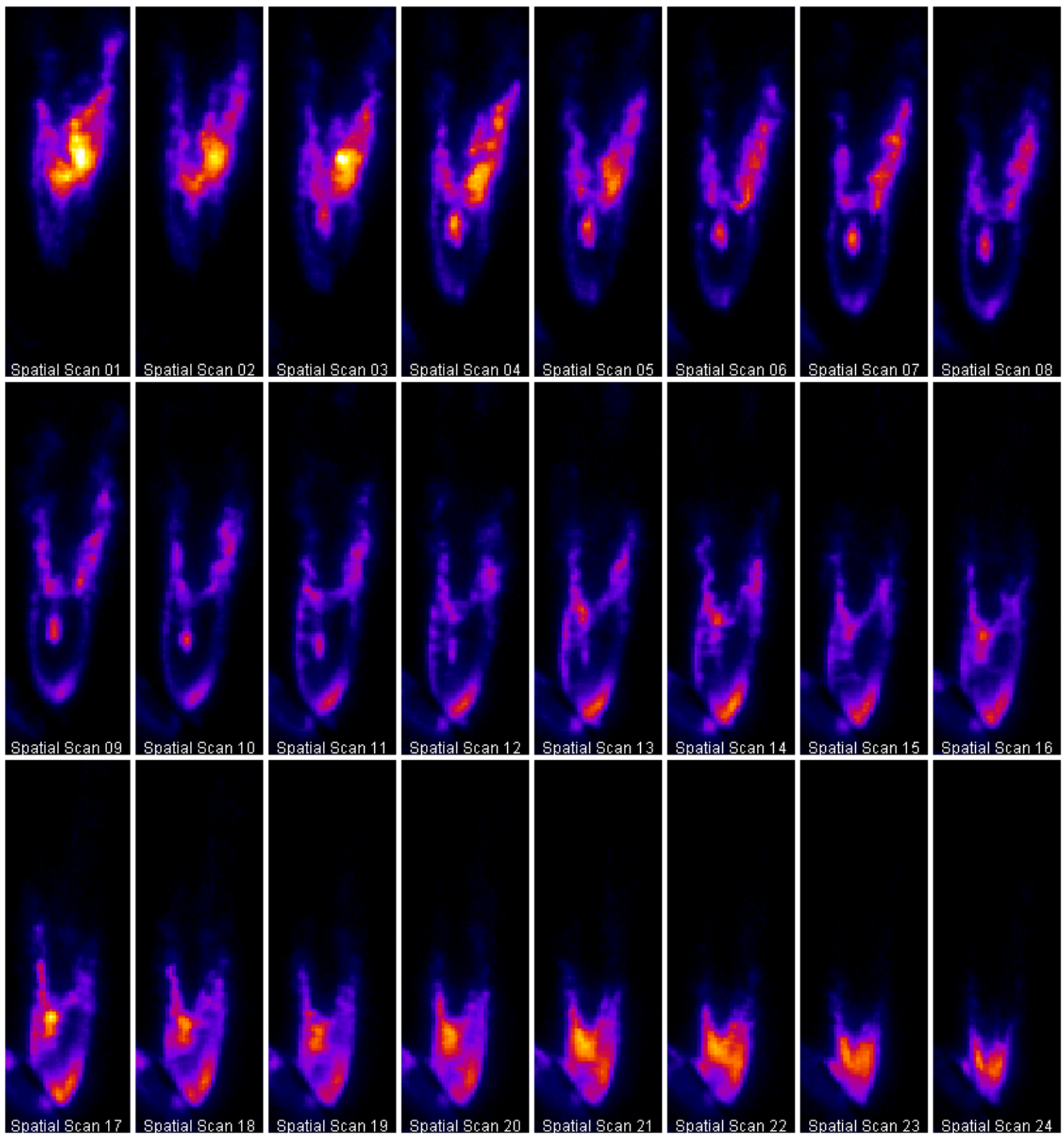

Figure 5: NO PLIF visualization of a spatial scan of the laser sheet through a 350 psia pitch down RCS jet flowing into stagnant air at a pressure of 0.77 psia; the jet pressure was held constant.

One interesting feature that was detected in these images was the large signal at the center of the jet, where the gas density should be very low and therefore there should be no PLIF signal. This can be seen clearly as the oval spot inside the barrel shock in images 6-11 of Figure 5. This centerline artifact could either be caused by condensation of the test gas or by a shock-focusing artifact owing to off-design operation of the nozzle. To explore these options an experiment was performed. Mie scattering from condensation would be independent of wavelength while increased levels of $\mathrm{NO}$ caused by shock-focusing would change intensity as the laser frequency changed. By scanning the frequency of the dye laser, the NO fluorescence intensity in the oval artifact was observed to vary proportionally with the signal produced by the rest of the jet. Thus, it was confirmed that the spot was indeed the result of a concentration of NO and not a Mie Scattering artifact. Such centerline artifacts are commonly observed when a converging-diverging nozzle is not operated at the design condition; shocks can begin to form on the surface 
of the converging section of the nozzle. These shocks will then focus together at some point beyond the exit of the nozzle, resulting in an anomalous high density region. This feature was not detected in any subsequent tests.

Figure 6 is a ViDI rendering of the capsule model at $18^{\circ}$ angle of attack with an NO PLIF visualization of an RCS roll jet pair at wind-off conditions. In this case the laser sheet was aligned with the center of the inner-most RCS roll jet exit nozzle, providing a visualization of the jet structure issuing from the roll jet nozzle. In this image the nozzle pressure was 833 psia and the ambient gas was $\mathrm{N}_{2}$ at 0.1 psia. As can be seen in the figure below, the roll RCS produces an underexpanded jet. Since the jets are pointed towards the centerline of the model, the signal intensity drops off moving away from the nozzle exit as the jet flows out of the image plane.

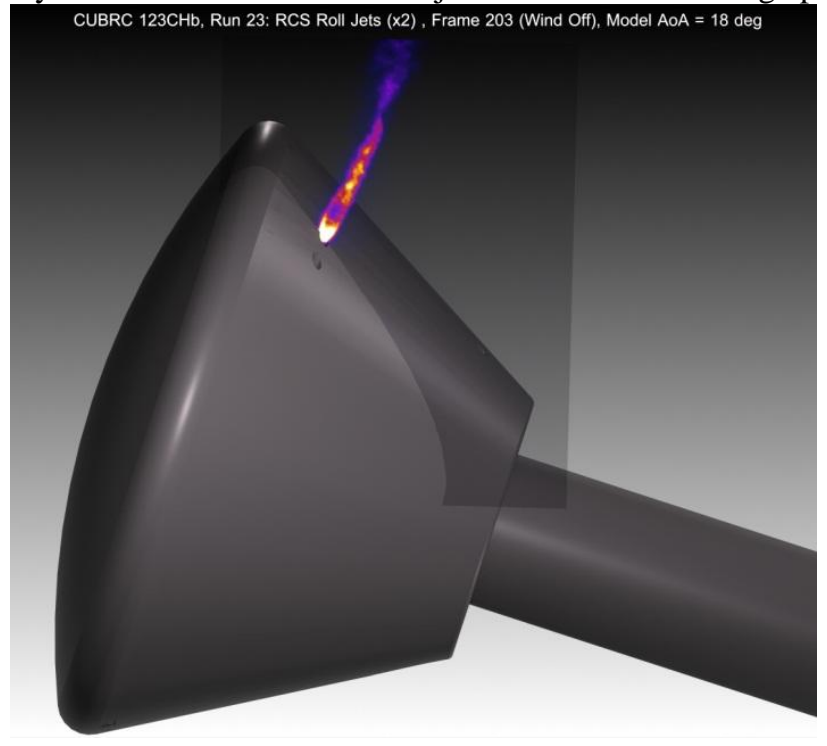

Figure 6: ViDI rendering of the capsule model at $18^{\circ} \mathrm{AoA}$ with NO PLIF visualization of a pair of 833 psia RCS roll jet pair flowing into stagnant $\mathrm{N}_{2}$ at a pressure of 0.1 psia.

In Figure 7 NO PLIF visualization was used to image an RCS pitch down jet at wind-off conditions. The model was held at an angle of attack of $18^{\circ}$ and the jet pressure was 878 psia. Since the laser sheet passes through the center of the pitch jet, the barrel shock and Mach disk can clearly be seen. In Figures 6 and 7, similar pressure ratios across the nozzle result in similar sized barrel shock structures.

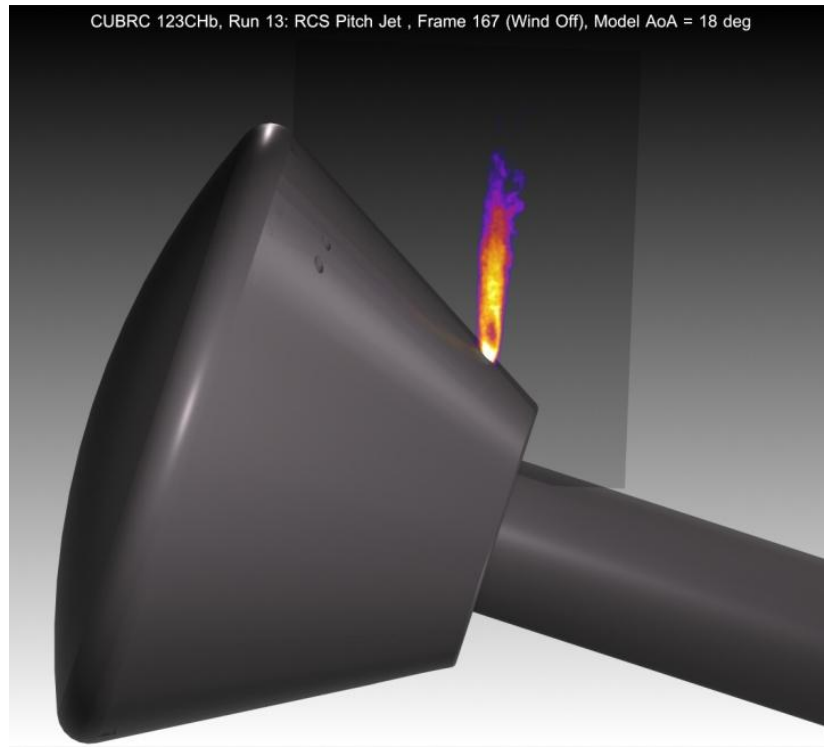

Figure 7: ViDI rendering of the capsule model at $18^{\circ}$ AoA with NO PLIF visualization of an 878 psia RCS pitch down jet flowing into stagnant $\mathrm{N}_{2}$ at a pressure of 1.2 psia. 
Figure 8 is another PLIF visualization depicting an RCS pitch down jet at wind-off conditions. In this case, however, the model angle of attack is $22^{\circ}$, the ambient pressure has decreased to $120 \mathrm{mTorr}\left(2.3 \times 10^{-3} \mathrm{psia}\right)$, and the jet pressure has decreased to $200 \mathrm{psia}$, resulting in a 10x larger pressure ratio across the nozzle. For this particular case, the composition of the jet fluid was $1 \% \mathrm{NO}$ and $99 \% \mathrm{~N}_{2}$. The classic underexpanded jet structure is still apparent but the barrel shock is much larger than the one seen in Figure 7 owing to the increased pressure ratio. In this case the Mach disk is located near the top of the image plane.

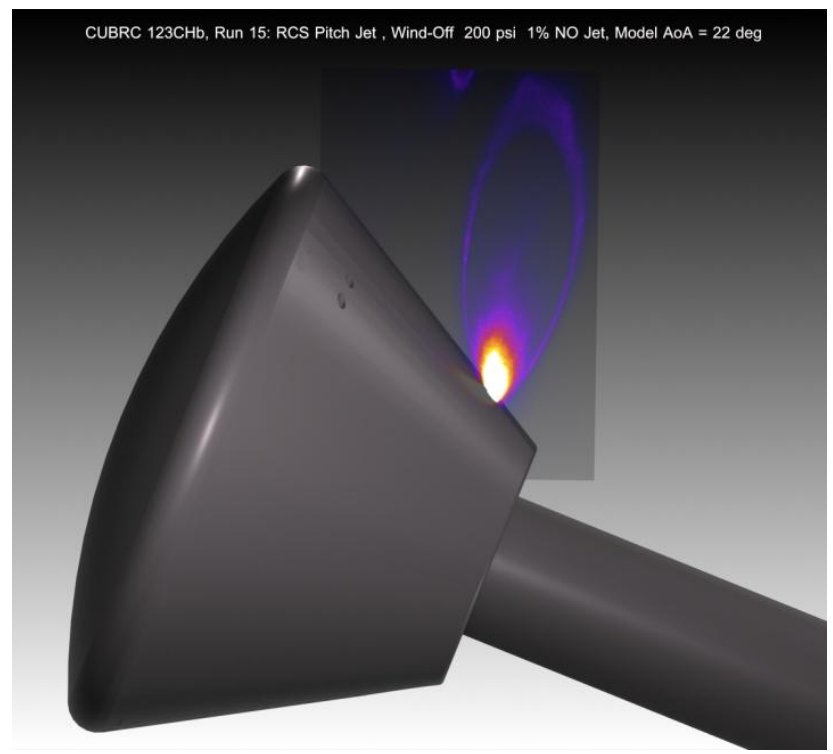

Figure 8: ViDI rendering of the capsule model at $22^{\circ}$ AoA with NO PLIF visualization of a 200 psia RCS pitch down jet flowing into stagnant air at a pressure of $2.3 \times 10^{-3}$ psia.

\section{B. Wind-on Measurements}

\section{Wind-on, RCS Jet-off measurements}

"Wind-on" images were taken in the test section of the CUBRC LENS-I facility with the facility operating normally. The nominal Mach number was 8 for all results presented herein while the free-stream Reynolds number based on model diameter was usually $2.2 \times 10^{6}$ and the test gas was $\mathrm{N}_{2}$ unless specified otherwise. In all images the free-stream flow is left-to-right.

To assist in understanding the NO PLIF flow visualizations, Schlieren images of the capsule shear layer were captured with no RCS jets firing. These images - shown in Figure 9-clearly depict the capsule shear layer and also demonstrate that the shear layer is unsteady. This shear layer forms when the fluid flowing over the leeward capsule shoulder does not have sufficient momentum to remain attached to the capsule afterbody, resulting in flow separation. The location of the shear layer appears to remain relatively constant near the capsule's leeward shoulder and fluctuates further downstream. This behavior is also apparent in Figure 10, which is a ViDI rendering of the capsule model at $18^{\circ}$ angle of attack with a time-averaged Schlieren image. In this averaged image the shear layer appears crisp and well defined near the leeward shoulder and becomes increasingly blurred as the flow travels downstream - the blurring taken as an indication of unsteadiness. 

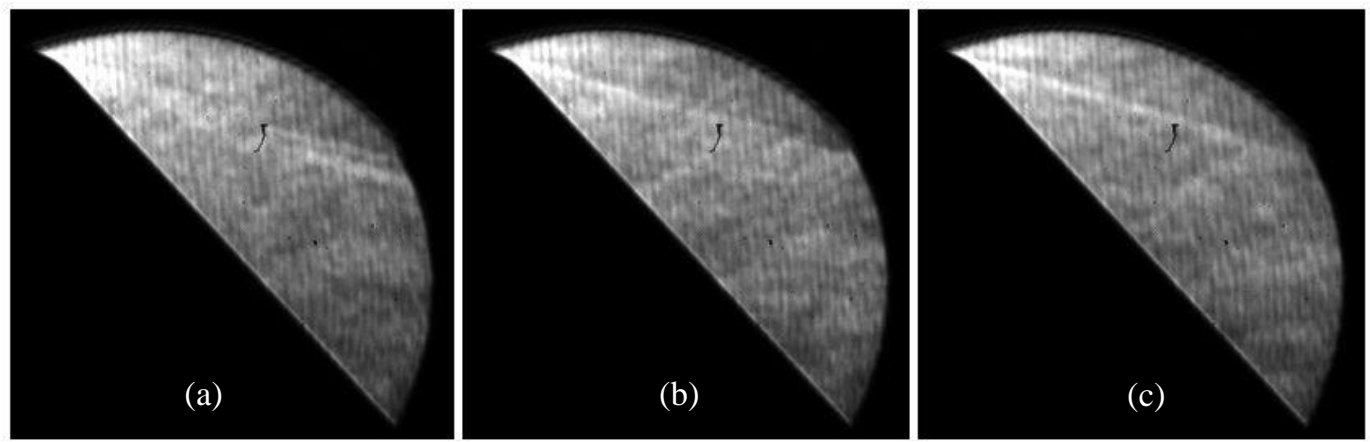

Figure 9: Raw Schlieren images depicting the shear layer emanating from the capsule model leeward shoulder with no RCS jets firing for the case of a free stream Mach number of 8 and $\operatorname{Re}_{D}=2.2 \times 10^{6}$.

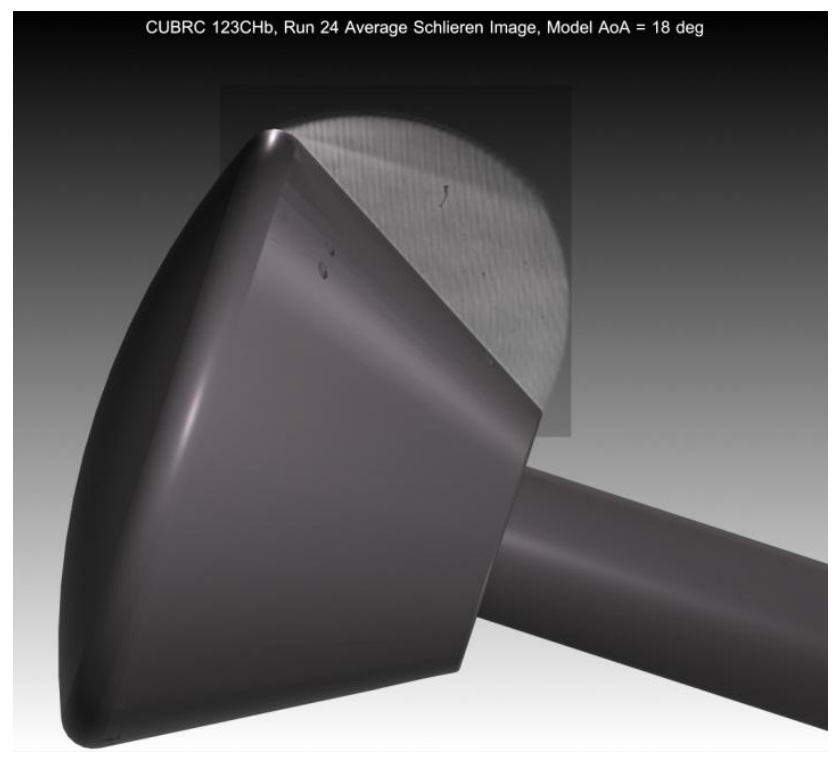

Figure 10: ViDI rendering of the capsule model at $18^{\circ}$ AoA with Schlieren visualization of leeward shoulder shear layer with no RCS jets firing averaged over 71 images for the case of a free stream Mach number of 8 and $\operatorname{Re}_{\mathrm{D}}=2.2 \times 10^{6}$.

Figure 11 presents a method of using PLIF to visualizing the shear layer generated by the capsule model for conditions where the RCS jets are not operating. As seen in later figures, it does not appear that active RCS jets have a significant impact on the angle of the shear layer. Here, a porous cylinder was used to seed NO gas into the flowfield. This flow was then entrained in the wake region, visualizing the shear layer. No RCS jets were firing during this case and the model was at an $18^{\circ}$ angle of attack. Additionally, in this image and many subsequent images, the PLIF intensity is presented on an arbitrary logarithmic scale in order to improve the visibility of the entire flowfield without saturating other parts of the image. In Figure 11, the PLIF visualization is superimposed on top of the Schlieren visualization from Figure 10. The PLIF visualization depicts the shear layer at approximately the same location as the time-averaged schlieren image. The comparison is particularly good near the shoulder of the capsule, as expected, considering that the shear layer appears to be more stable at this location. The unsteadiness further downstream is apparent in the PLIF image as well. The shear layer appears to bend upwards and the NO gas is distributed non-uniformly towards the aft of the capsule in this instantaneous image. 


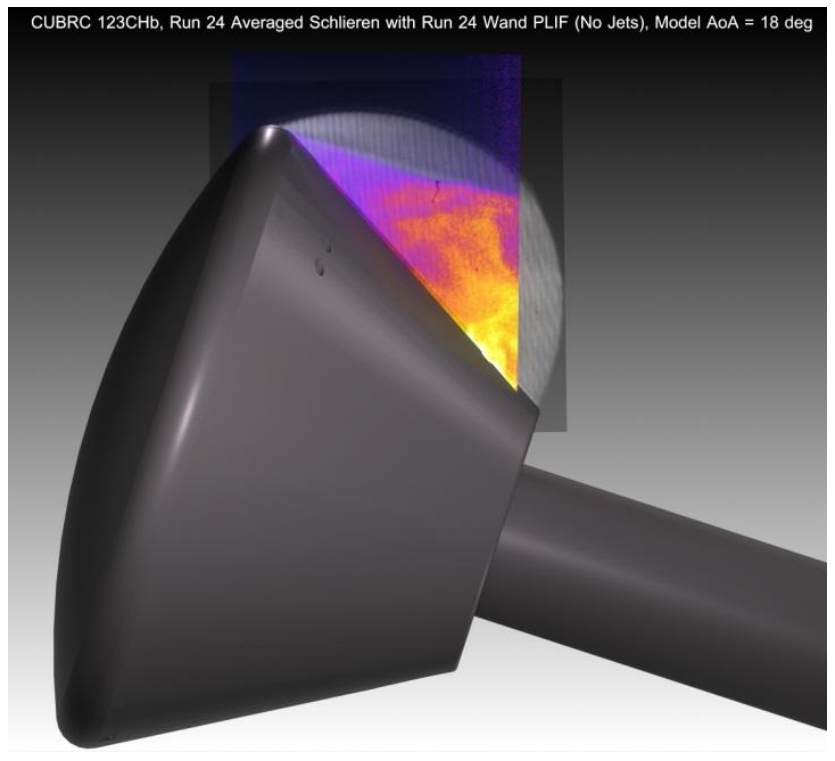

Figure 11: ViDI rendering of the capsule model at $18^{\circ}$ AoA with time-averaged Schlieren and instantaneous PLIF visualization of the leeward shoulder shear layer with no RCS jets firing for the case of a free stream Mach number of 8 and $\operatorname{Re}_{\mathrm{D}}=2.2 \times 10^{6}$.

Figure 12 compares two porous cylinder-seeded shear layer visualizations. In both images the model is at $18^{\circ}$ angle of attack and the model has been rotated $180^{\circ}$ about its centerline so the RCS jets (not activated) face downward. Figure 12(a) the free stream Reynolds number based on model diameter of $2.2 \times 10^{6}$. In Figure 12(b), however, the free stream Reynolds number has been increased to $1.5 \times 10^{7}$. As seen in the image, this increase in Reynolds number has a significant impact on the nature of the wake region. First, there are smaller-scale structures resembling turbulent flow throughout the wake region in image (b), while image (a) consists of larger scale, more laminar, perhaps transitional, structures. Additionally, while the shear layer appears to be laminar near the lip of the capsule it appears to begin to transition around the center of the image. At the furthest point downstream in image (b) the shear layer shows clear signs of turbulence.

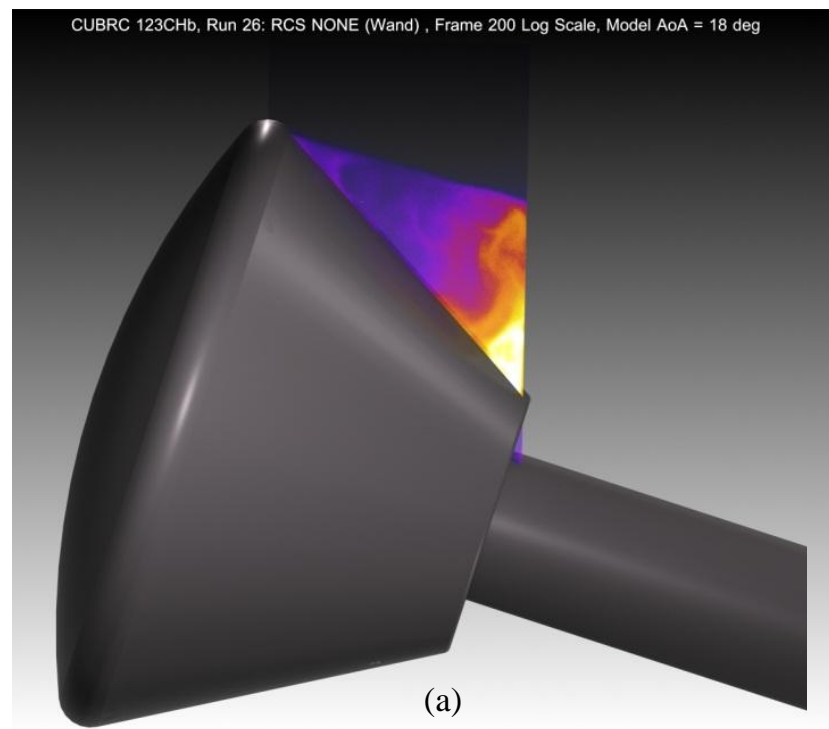

CUBRC 123CHb, Run 27: RCS NONE (Wand) , Frame 189 Log Scale, Model AoA $=18$ deg

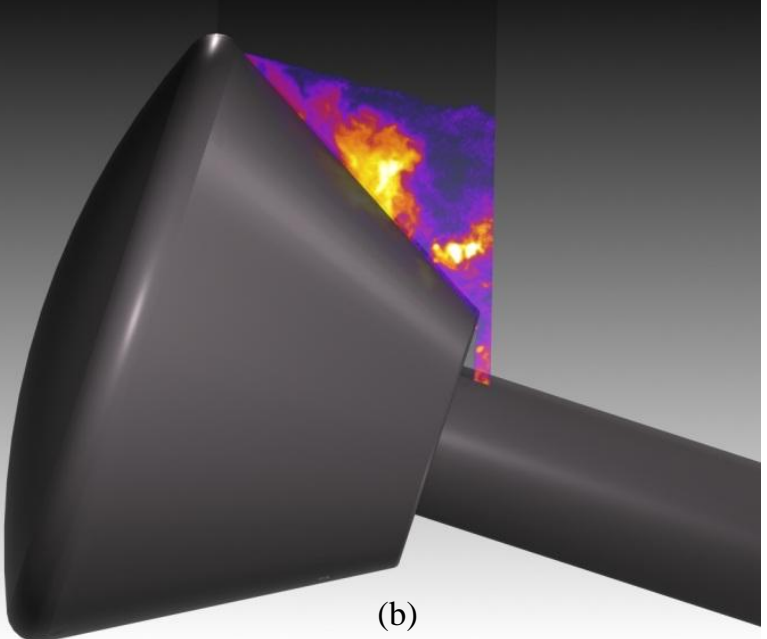

Figure 12: ViDI renderings of the capsule model at $18^{\circ}$ AoA with PLIF visualization of the leeward shoulder shear layer with no RCS jets firing and the model rotated $180^{\circ}$ for the case of a free stream Mach number of 8 and (a) $\operatorname{Re}_{D}=2.2 \times 10^{6}$ (b) $\operatorname{Re}_{\mathrm{D}}=1.5 \times 10^{7}$. 
Figure 13 is a comparison of two ViDI renderings of the capsule model with NO PLIF visualization of the surrounding flowfield. In both images, the test gas was air, the Reynolds number based on model diameter was 2.2 $\mathrm{x} 10^{6}$, and the enthalpy was $3 \mathrm{MJ} / \mathrm{kg}$ (compared to ?? $\mathrm{MJ} / \mathrm{kg}$ for all other runs). Owing to the high enthalpy condition and the use of $0.5 \% \mathrm{O}_{2}, 99.5 \% \mathrm{~N}_{2}$ as the test gas, $\mathrm{NO}$ was generated naturally in the flow. This allowed for NO PLIF to be performed without seeding any gas into the flow. As was previously mentioned, under these conditions the laser had to be tuned to excite the $\mathrm{R}_{2}(13.5)$ line in order for sufficient laser energy to be transmitted to the camera FOV near the model. The main difference between the two images in the figure below is that in image (a) the model was at $18^{\circ}$ angle of attack while in image (b) the model was at $22^{\circ}$ angle of attack. (Another difference was that for (a) the laser energy was about three times higher than (b), resulting in a higher signal-tonoise image.)

There are three main flow features that can be seen in both images. First, an expansion fan on the leeward shoulder of the model appears as a region of relatively high intensity to the far left of the image plane in (a) and (b). Next, a lip shock, which is the result of the flow around the model overexpanding, can be seen as a faint line emanating from the leeward shoulder of the model at approximately $50^{\circ}$ with respect to the backshell surface normal. Lastly, the shear layer also appears as a second faint line emanating from the leeward shoulder of the model at approximately $30^{\circ}$ with respect to the backshell surface normal. These images appear qualitatively very similar and it appears that the $4^{\circ}$ change in angle of attack has little impact on the flow structure downstream of the model. The shear layer in Figure 13(a) is very similarly located that to Error! Reference source not found.(a) and Figure 10 (the same case but at lower enthalpy). This implies that the three imaging techniques-Schlieren, externally seeded NO PLIF, and NO PLIF of naturally occurring NO-show agreement with respect to the location of the leeward shoulder shear layer.

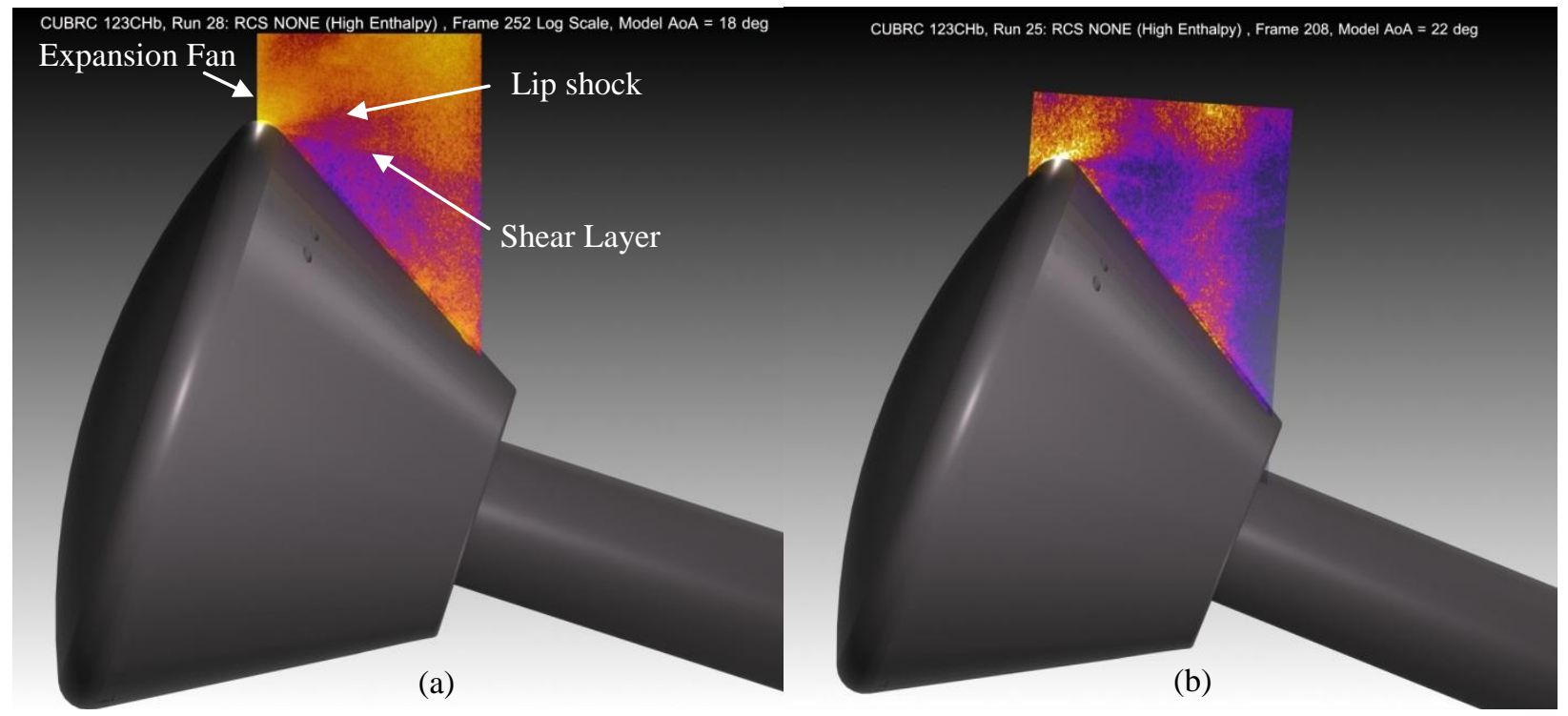

Figure 13: ViDI renderings of the capsule model at (a) $18^{\circ} \mathrm{AoA}$ and (b) $22^{\circ} \mathrm{AoA}$ with PLIF visualization of the leeward shoulder shear layer using only naturally occurring NO in the flow for a high enthalpy case with a free stream Mach number of 8 and $\operatorname{Re}_{\mathrm{D}}=2.2 \times 10^{6}$.

\section{Wind-on, RCS jet-on measurements}

Figure 14 below shows a pair of 833 psia gaseous jets issuing from the RCS roll jet nozzles into a 0.1 psia Mach 8 flowfield. In order to collect this image the laser sheet was positioned so that it was centered on the roll jet nearest to the model centerline. The classic structure of an under-expanded jet is evident in the figure. Also, the jet fluid almost immediately interacts with the fluid flowing around the lip of the model and completely loses its barrel structure. The location of the shear layer is clearly marked by the diagonal line that streaks across the structure of the roll jet. After interacting with the shear layer the roll jet fluid is swept downstream and very little of it travels transversely across the model, as evidenced by Figure 15 (discussed below). However, it is unclear if this interaction is causing the shear layer to become turbulent or simply unsteady. 


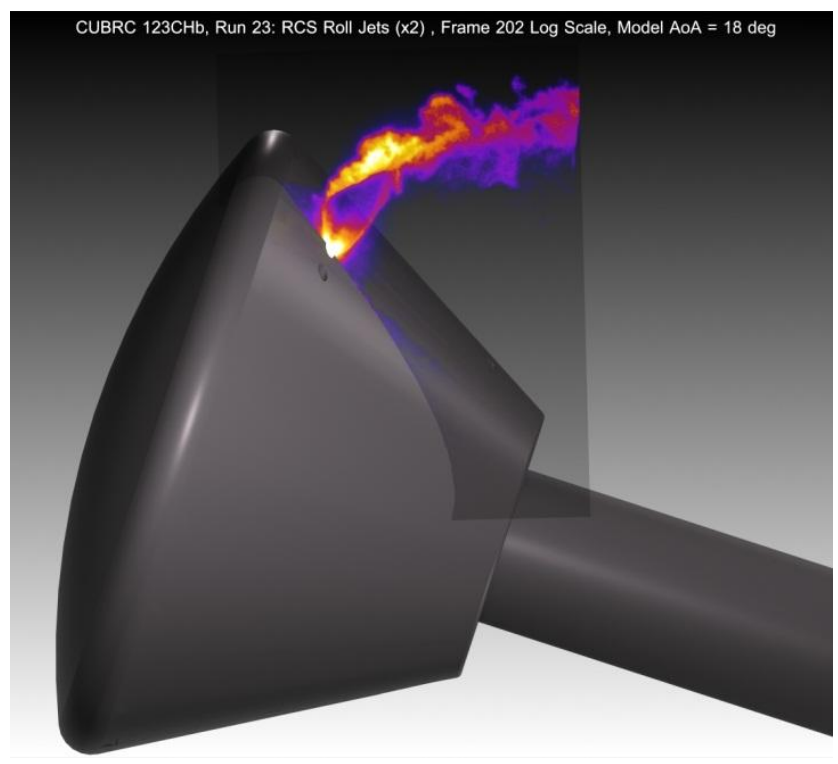

Figure 14: ViDI rendering of the capsule model at $18^{\circ}$ AoA with NO PLIF visualization of an 833 psia RCS roll jet pair issuing into a 0.1 psia Mach 8 flowfield.

Figure 15 is an NO PLIF visualization of a pair of RCS roll jets firing on a capsule model at an $18^{\circ}$ angle of attack with the laser sheet positioned on the center of one of the pitch jet nozzles (as in Figure 4) close to the nozzle centerline. Since the laser sheet is positioned far from the roll jet nozzles, the underexpanded jet structure is not visualized in this image. However, fluid from the jets still crosses the laser sheet downstream of the nozzles. In Figure 15 the jets no longer propagate normal to the model surface and it is clear that the flow has bent the path of the roll jet pair significantly. The structures visualized in Figure 15 appear to be turbulent, much like the structures found downstream of the jet exits in Figure 14. The nature of the shear layer, be it laminar, transitional, or turbulent, is difficult to determine from the available image. Based on Figure 14 and Figure 15 it appears that the jets are able to maintain their structure beneath the shear layer but once they penetrate the shear layer and enter the higher momentum flow the jets break down into turbulence.

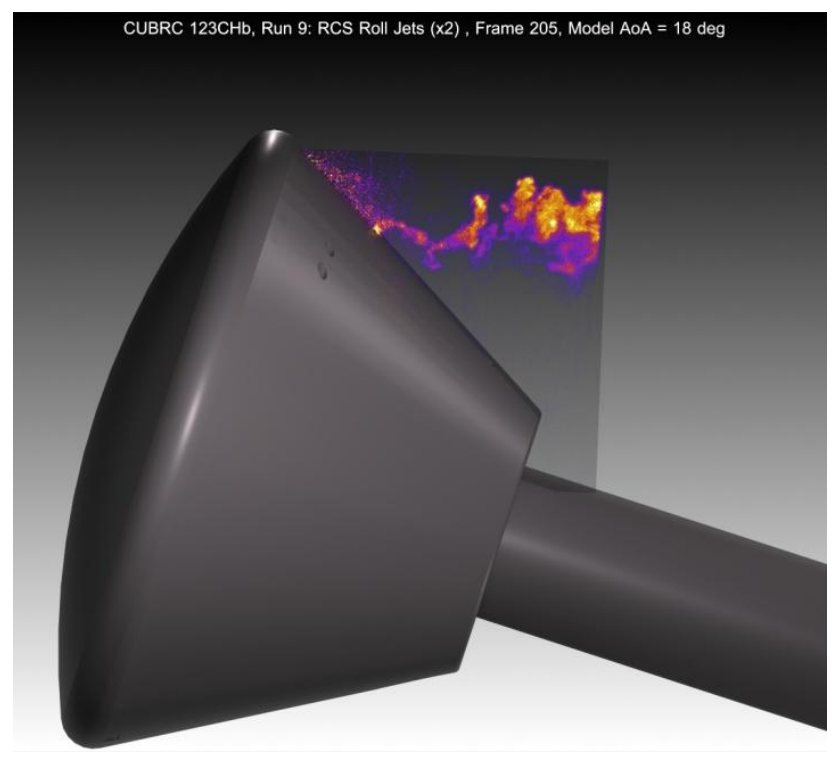

Figure 15: ViDI rendering of the capsule model at $18^{\circ}$ AoA with NO PLIF visualization of a 372 psia RCS roll jet pair issuing into a 0.6 psia Mach 8 flowfield. 
Figure 16 is a ViDI rendering of the capsule model at an $18^{\circ}$ angle of attack that combines NO PLIF flow visualization of dual RCS roll jets with a time-averaged Schlieren image of the shear layer emanating from the capsule's leeward shoulder collected while no RCS jets were firing. Since the PLIF signal was low in the vicinity of the capsule shoulder in Figure 15 it was helpful to combine this with the Schlieren visualization to better understand how the roll jets interacted with the shear layer. As can be seen in Figure 16, the jet fluid remains primarily inside the jet-off wake region. While the jet is within the wake region, one can imply that its structure remains relatively compact based on the evidence in Figure 14 and considering how little fluid reaches the laser sheet in the figure below.

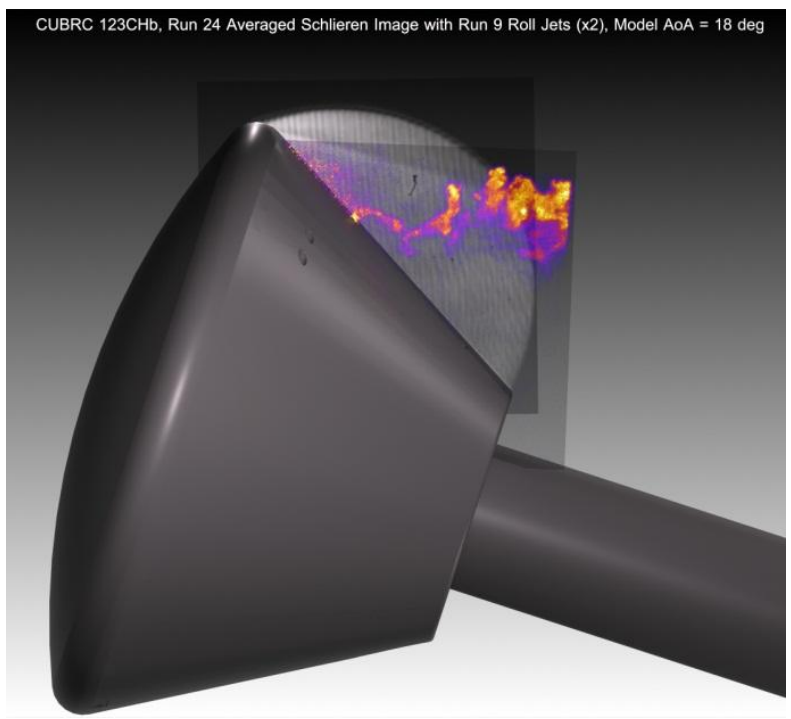

Figure 16: ViDI rendering of the capsule model at $18^{\circ}$ AoA with NO PLIF visualization of a 372 psia RCS roll jet pair issuing into a 0.6 psia Mach $8\left(\operatorname{Re}_{\mathrm{D}}=2.2 \times 10^{6}\right)$ flowfield combined with time-averaged schlieren visualization of the shear layer in a Mach $8\left(\operatorname{Re}_{\mathrm{D}}=2.2 \times 10^{6}\right)$ flowfield.

Figure 17 is a visualization of an RCS pitch down jet with an exit pressure of 1030 psia exhausting into a Mach 8 flow. In this case the capsule model was still held at an $18^{\circ}$ angle of attack. Once again, the jet is underexpanded and the barrel shock and Mach disk are evident. The shear layer is much more defined in this image than the one in Figure 15, because it appears that significantly more NO is entrained near the model centerline during pitch-down jet firing than with roll jet firing. Additionally, the shear layer appears to be laminar and the wake region between the capsule shoulder and jet is most likely a clockwise recirculation zone. Fluid from the jet is entrained in this region where it travels along the capsule afterbody towards the leeward shoulder. As the fluid approaches the shear layer boundary, the flow circles back in the direction of the free-stream. It is possible that a portion of the jet fluid is actually impinging on the surface of the capsule afterbody. Also notice that almost no jet fluid propagates downstream of the nozzle exit in the wake region. This also enforces the idea that the flow along the capsule afterbody is moving towards the capsule shoulder. The structure of the edges of the pitch jet appears turbulent even before exiting the wake region, but the flow is laminar near the nozzle exit and in the center of the RCS jet. Once the jet penetrates the shear layer it loses definition and the fluid takes a similar form to the roll jets seen in Figure 15. An interesting feature that can be seen in Figure 17 is the set of outer structures on either side of the barrel shock of the pitch jet. This is most likely the shear layer of the underexpanded jet, a result of the discontinuity between the jet flow processed by the barrel shock and the wake region on the capsule afterbody. The possibility of the feature being the artifact of some sort of reflection off of the model can be ruled out given that the flanges do not appear on any of the wind-off images. 


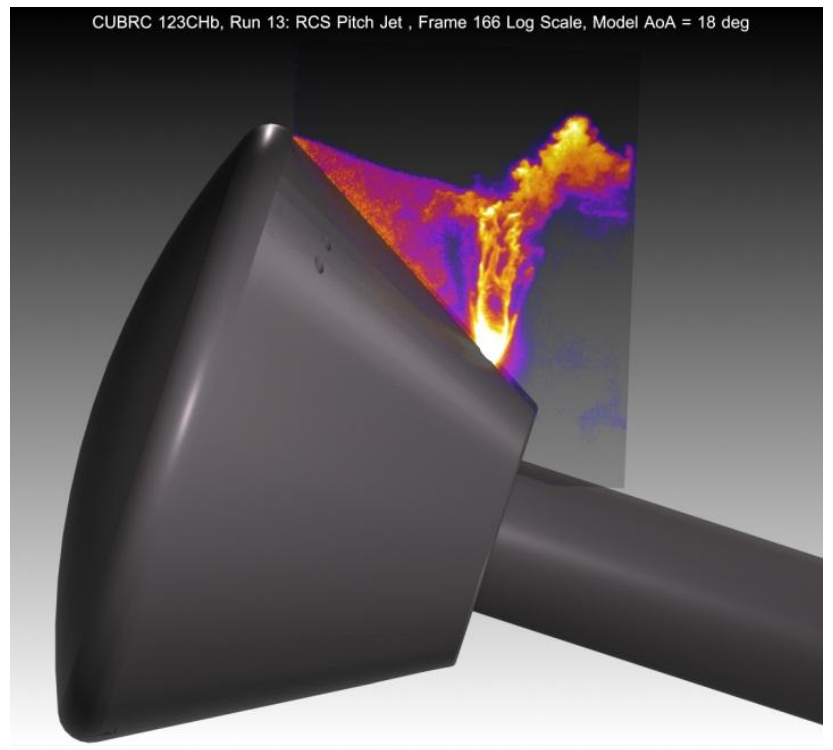

Figure 17: ViDI rendering of the capsule model at $18^{\circ}$ AoA with NO PLIF visualization of an 878 psia RCS pitch down jet issuing into a 1.2 psia Mach 8 flowfield.

In Figure 18, NO PLIF was used to visualize the firing of an RCS pitch down jet pair into a Mach 8 supersonic flow at (a) $18^{\circ}$ angle of attack and (b) $22^{\circ}$ angle of attack. For both cases, the pitch jets were pressurized by a plenum at 888 psia and exhausted into a 0.10 psia aft-body environment. The $4^{\circ}$ change in angle of attack seems to have changed the flowfield very little when comparing Figure 18(a) and Figure 18(b). The underexpanded jet structure is once again apparent in both cases in Figure 18, however, the jet structure appears quite different than the one visualized for the single pitch down jet case seen in Figure 17. The two jets may be interacting with each other in such a way that the jet structure is altered. Additionally, some jet fluid penetrates the shear layer in both cases and the jet structure is completely dissipated upon exiting the shear layer. Fluid from the pitch jets is again entrained in the wake region in Figure 18(a) and Figure 18(b), allowing visualization of the shear layer. The shear layer seems to be laminar but has a slightly convex shape in both instances. One of the few differences between the two figures is in the visualization of the shear layer. First, the shape of the shear layer is different when comparing the two images, as the shear layer has a more dramatic bend in Figure 18(b) than it does in Figure 18(a). It is difficult to determine what this means with only two images of a pitch jet pair, as this may be a result of unsteadiness in the shear layer captured in an instantaneous frame as opposed to a steady-state feature of the shear layer itself. Additionally, higher signal intensities are present in the shear layer in the $18^{\circ}$ case than the $22^{\circ}$ case. This may mean that more jet fluid is entrained in the shear layer at $18^{\circ}$ angle of attack but may simply be a result of inconsistent laser energy between runs or unsteadiness in the flow. Another interesting feature of the shear layer is the gradient in signal intensity seen moving from the capsule shoulder (high intensity) to just upstream of the jet (lower intensity) seen at both $18^{\circ}$ and $22^{\circ}$ angle of attack. Lastly, the "flanges" seen in Figure 17 resembling the jet shear layer cannot be seen in either case in Figure 18. It may be possible that the jet shear layer was only seen in Figure 17 because of unusually high signal counts. However, it could be that an interaction between the jets exists in the dual jet case that prevents the jet shear layer from being visualized. 

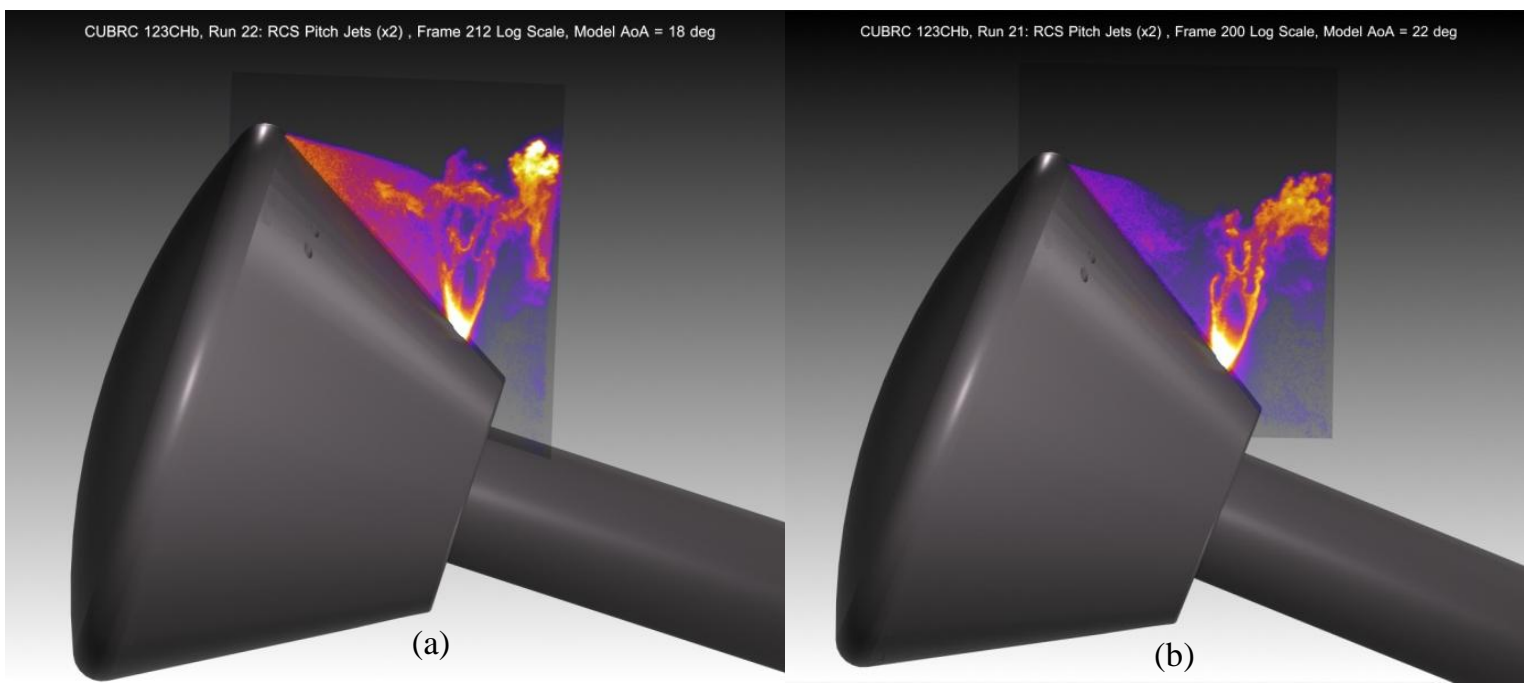

Figure 18: ViDI renderings of the capsule model at (a) $18^{\circ} \mathrm{AoA}$ and (b) $22^{\circ} \mathrm{AoA}$ with NO PLIF visualization of a 790 psia RCS pitch down jet pair issuing into a 0.1 psia Mach 8 flowfield.

Figure 19 compares the NO PLIF visualization of an RCS pitch down jet pair at $22^{\circ}$ angle of attack with a timeaveraged Schlieren visualization collected during the same run. The expansion fan, lip shock (faint) and shear layer can all be seen in Figure 19(b). Additionally, the average structure of the underexpanded pitch jet can clearly be observed. The most interesting thing about this image, though, is that it is one of the few cases during this experimental campaign that the visualization of the shear layer from two separate techniques did not match. As mentioned above, it is strange that the shear layer in Figure 19(a) has a sharp bend about halfway between the capsule lip and pitch jet. However, this feature does not appear in the time-averaged schlieren image. Considering that image (a) is an instantaneous image, and image (b) is an averaged over 73 images, it is most likely that image (a) happened to be collected at an instant of particularly high instability in the shear layer while image (b) provides a more accurate representation of the mean flow structure.
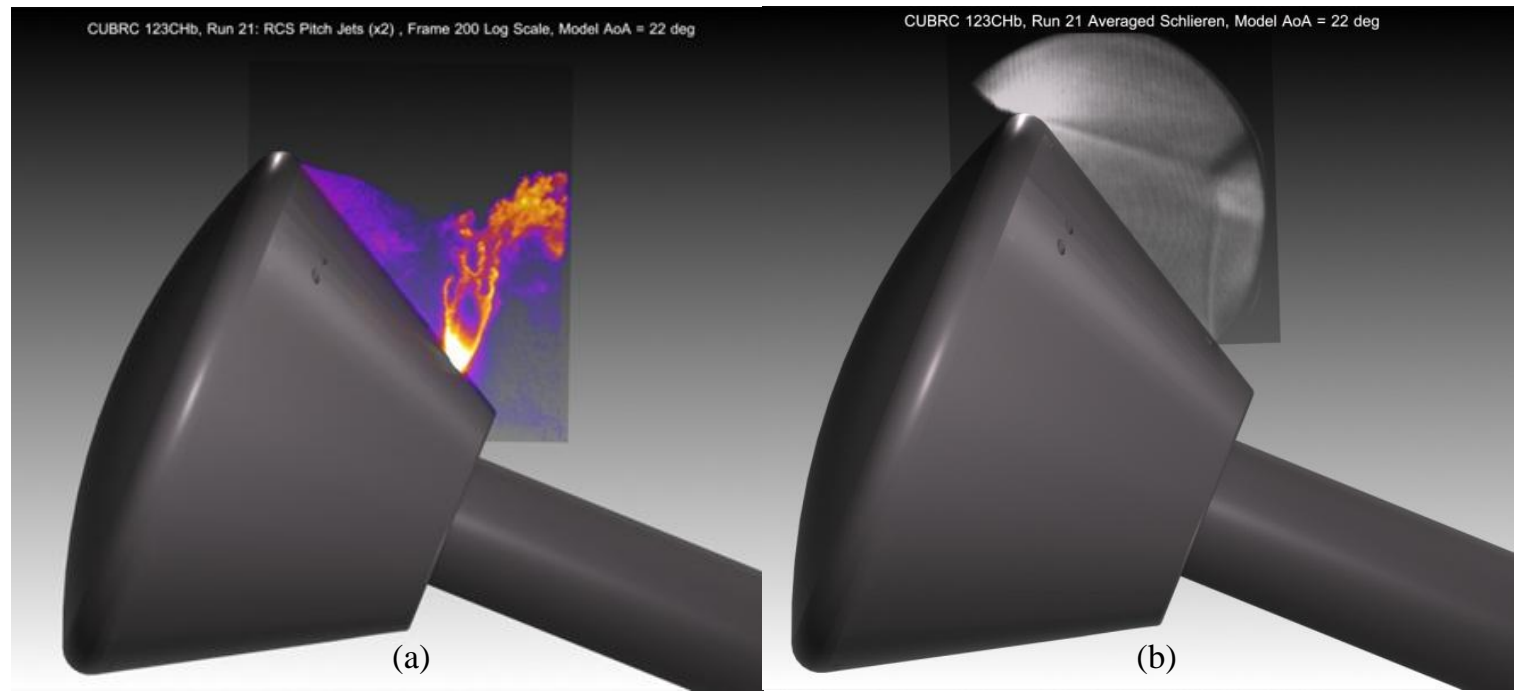

Figure 19: ViDI renderings of the capsule model at $18^{\circ}$ AoA with (a) NO PLIF and (b) Schlieren visualization of a 790 psia RCS pitch down jet pair issuing into a 0.1 psia Mach 8 flowfield.

Figure 20 is a ViDI rendering of the capsule model at a $22^{\circ}$ angle of attack with an NO PLIF visualization of RCS pitch down and RCS roll jets firing simultaneously in a Mach 8 supersonic flow. The pitch and roll jets were pressurized by a 368 psia plenum. As one might expect, Figure 20 is a sort of superposition of Figure 15 and Figure 17. First, the underexpanded jet from the RCS pitch down barrel shock and Mach disk is clearly seen. Also, there is an increased amount of fluid in the wake region compared to Figure 17, most likely as a result of the RCS roll jets 
firing. The pitch jet still penetrates the shear layer but it appears that the interaction with the roll jet causes its structure to break down much sooner than in Figure 17 which was obtained at the same Reynolds number. The roll jet pair also seems to trip the shear layer into turbulence, as seen in Figure 15.

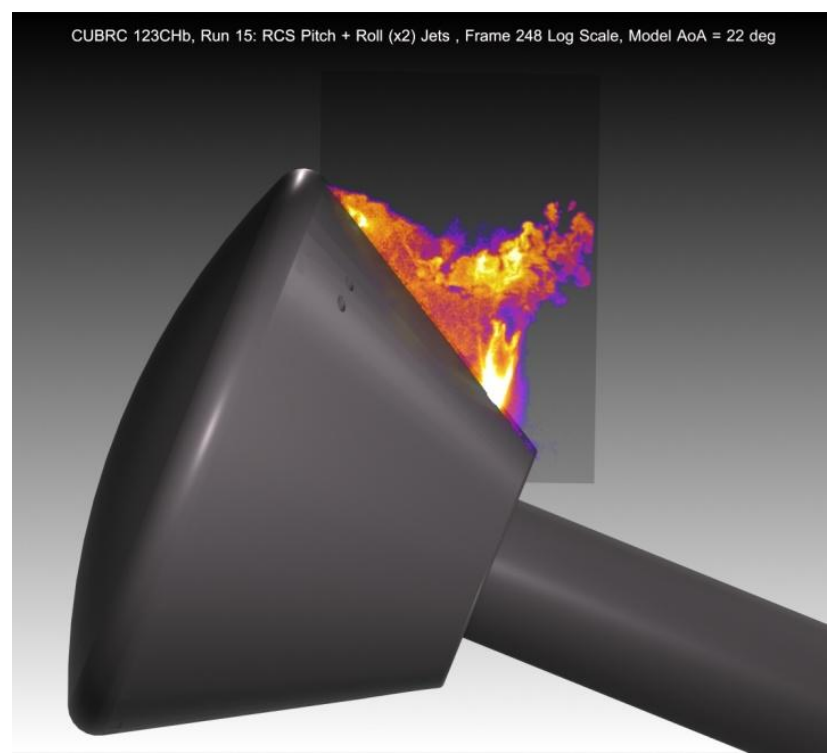

Figure 20: ViDI rendering of the capsule model at $22^{\circ} \mathrm{AoA}$ with NO PLIF visualization of a 368 psia RCS pitch down jet and 0.1 psia RCS roll jet pair issuing into a Mach 8 flowfield.

\section{Wind-On Heat Transfer Measurements}

Figure 21 shows a series of ViDI renderings of the capsule model at an $18^{\circ}$ angle of attack in a Mach 8 flowfield with free stream Reynolds number based on model diameter of (a) $2.2 \times 10^{6}$, (b) $4.0 \times 10^{6}$, (c) $6.0 \times 10^{6}$, and (d) 8.0 $\mathrm{x} 10^{6}$. Heat transfer data collected by a network of thin film sensors is superimposed on the surface of the capsule model. No RCS jets were firing during acquisition of this data. The black spots on the surface of the model indicate the locations of the RCS roll and pitch-down jet nozzles. First, as expected, heating is fairly uniform and symmetrical for all four cases. The reattachment point, where flow from the windward side of the model attaches to the capsule afterbody, causes a significant heating increase and is especially evident in Figure 21(c) and Figure 21(d). Additionally, all four images show elevated heating values in the vicinity of the pitch down jets (which were not operating). As expected, mean heat transfer rates along the upper-half of the capsule afterbody increased as the free stream Reynolds number increased. Measured heat transfer values are summarized in Table 2 below. Lastly, Figure 21(a) is of special importance to this study, as the figure provides a control case for the heat transfer data collected during runs at $18^{\circ}$ angle of attack given that the Reynolds number and Mach number are the same as in the runs with RCS jets firing. It is clear in Figure 21(a) that the heat transfer is essentially uniform across the upper-half of the capsule afterbody and therefore any variations in the heat transfer measured across the surface of the capsule with the RCS jets firing can be attributed to changes to the flowfield derived from the jets. It should be noted that the triangular shapes in the heat transfer map are unphysical artifacts stemming from the way that the data from the grid of thin film sensors was converted into a three-dimensional contour map. 


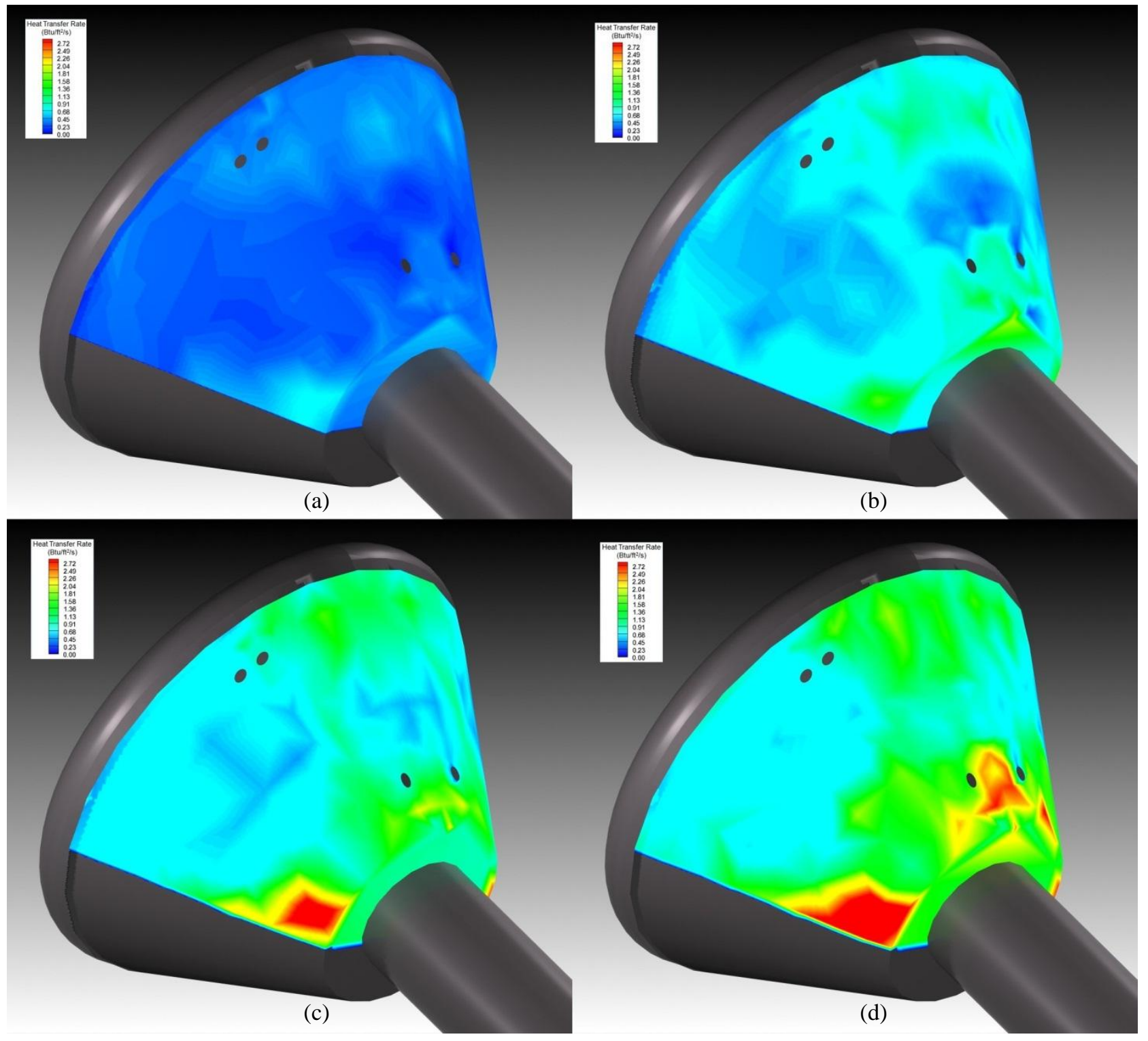

Figure 21: ViDI renderings of the capsule model at $18^{\circ} \mathrm{AoA}$ in a Mach 8 flowfield with Reynolds number based on model diameter of (a) $2.2 \times 10^{6}$, (b) $4.0 \times 10^{6}$, (c) $6.0 \times 10^{6}$, and (d) $8.0 \times 10^{6}$. Heat transfer data $\left(\mathrm{Btu} / \mathrm{ft}^{2} / \mathrm{s}\right)$ collected by a network of discrete thin film sensors is displayed on the surface of the model. 


\begin{tabular}{|c|c|c|c|c|c|c|c|}
\hline \multirow{2}{*}{ Run Number } & \multirow{2}{*}{ RCS Jets } & \multirow{2}{*}{$\mathbf{R e}_{\mathbf{D}}$} & \multirow{2}{*}{$\mathbf{A 0 A}\left({ }^{\circ}\right)$} & \multicolumn{2}{|c|}{ Max } & \multicolumn{2}{c|}{ Average } \\
\cline { 5 - 8 } & & & & $\mathrm{Btu} / \mathrm{ft}^{2} / \mathrm{s}$ & $\mathrm{W} / \mathrm{m}^{2}$ & $\mathrm{Btu} / \mathrm{ft}^{2} / \mathrm{s}$ & $\mathrm{W} / \mathrm{m}^{2}$ \\
\hline 4 & None & $2.2 \times 10^{6}$ & 18 & 0.645 & 7325 & 0.260 & 2953 \\
\hline 2 & None & $4.0 \times 10^{6}$ & 18 & 1.85 & 21010 & 0.637 & 7234 \\
\hline 3 & None & $6.0 \times 10^{6}$ & 18 & 3.63 & 41224 & 0.935 & 10618 \\
\hline 1 & None & $8.0 \times 10^{6}$ & 18 & 3.96 & 44972 & 1.22 & 13855 \\
\hline 9 & Roll (x2) - 372 psia & $2.2 \times 10^{6}$ & 18 & 1.77 & 20101 & 0.435 & 4940 \\
\hline 10 & Roll (x2) - 821 psia & $2.2 \times 10^{6}$ & 18 & 3.07 & 34864 & 0.480 & 5451 \\
\hline 23 & Roll (x2) - 833 psia & $2.2 \times 10^{6}$ & 18 & 2.87 & 32590 & 0.473 & 5370 \\
\hline 13 & Pitch & $2.2 \times 10^{6}$ & 18 & 2.68 & 30435 & 0.427 & 4849 \\
\hline 22 & Pitch (x2) & $2.2 \times 10^{6}$ & 18 & 9.72 & 110380 & 0.640 & 7270 \\
\hline 21 & Pitch (x2) & $2.2 \times 10^{6}$ & 22 & 11.07 & 125720 & 0.544 & 6180 \\
\hline 15 & Roll (x2)/Pitch (1) & $2.2 \times 10^{6}$ & 22 & 1.77 & 20100 & 0.424 & 4810 \\
\hline
\end{tabular}

Table 2: Summary of measured heat transfer values for various test conditions.

Figure 22 shows two ViDI renderings of the capsule model at $18^{\circ}$ angle of attack that combine an NO PLIF flow visualization with simultaneous heat transfer data. The flow visualizations depict (a) 372 psia (the same image shown in Figure 15) and (b) 821 psia RCS roll jets issuing into a Mach 8 flowfield. The path of the roll jet pair's interaction on the afterbody of the capsule is evident in Figure 22. According to the heat transfer data, the jets issue from the nozzle, initially perpendicular to the free-stream flow direction. As the roll jet pair interacts with the freestream flow, it turns to align with the flow and the fluid travels downstream. While this is consistent with previous research on afterbody heating resulting from RCS jets, ${ }^{3,8,9}$ it does not correlate well with the PLIF data. The large amount of heating nearest to the roll jet nozzle exit and adjacent to the plane of the laser sheet would seem to imply that there is a significant quantity of jet fluid passing over the model surface at this location. However, this fluid does not appear in the PLIF image. Considering that both images depict highly similar heating footprints one can conclude that this is no anomaly. It may be that the primary heating is not necessarily the result of the jet fluid interacting with the capsule surface but is instead caused by vortices in the wake region generated by the passing jet fluid. Fluid from the wake region could be rolled up around the path of the roll jets, somewhat like a horseshoe vortex, and thus heating the model surface. This would also be consistent with the heating concentration adjacent to the capsule's leeward shoulder. For the 372 psia jet pair, peak heating values of $1.77 \mathrm{Btu} / \mathrm{ft}^{2} / \mathrm{s}\left(20.10 \mathrm{~kW} / \mathrm{m}^{2}\right)$ were measured at this location, while peak heating values of $3.07 \mathrm{Btu} / \mathrm{ft}^{2} / \mathrm{s}\left(34.86 \mathrm{~kW} / \mathrm{m}^{2}\right)$ were measured for the $821 \mathrm{psia}$ jet pair. At this location, rapidly expanding jet fluid emanating from the roll jet nozzle blocks the oncoming flow, causing it to stagnate and recirculate just upstream of the nozzle, leading to high levels of heating. The heating was higher in the 821 psia jet case as a result of the higher pressure jet generating more turbulent structures in the wake region. 


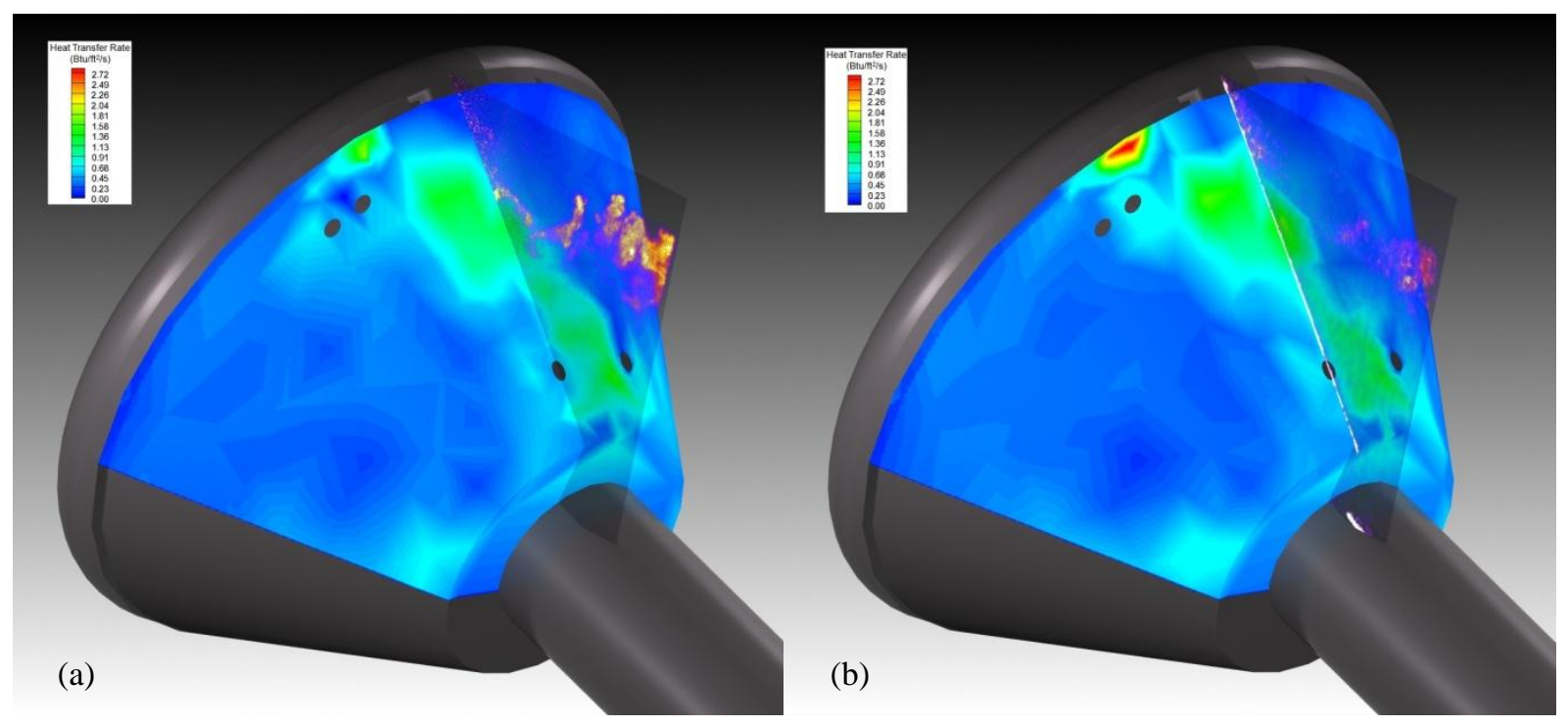

Figure 22: ViDI renderings of the capsule model at $18^{\circ}$ AoA with NO PLIF visualization of (a) 372 psia and

(b) 821 psia RCS roll jet pair issuing into a Mach 8 flowfield. Heat transfer data $\left(\mathrm{Btu} / \mathrm{ft}^{2} / \mathrm{s}\right)$ collected simultaneously by a network of thin film sensors is displayed on the surface of the models.

Figure 23 is a ViDI rendering of the capsule model at $18^{\circ}$ angle of attack with NO PLIF visualization of an RCS roll jet pair at two separate imaging planes. One plane is centered on the left pitch down jet while the second plane is located on the inner-most roll jet. On the surface of the model, contours of heat transfer rate $\left(\mathrm{Btu} / \mathrm{ft}^{2} / \mathrm{s}\right)$ are displayed. The heat transfer map was collected during a run where an 833 psia roll jet pair was fired. Considering the similar run conditions, it is no surprise that the heat transfer map on Figure 23 is almost identical to the one seen in Figure 22(b). Having the two image planes along with the heat transfer contours illustrates the previous point that the roll jet fluid is not necessarily impinging on the surface and heating the flow. If this were the case, there would be quantities of fluid visible at the shoulder of the model in the first image and along the model surface in the second image plane. This heating must be the result of a secondary flow structure generated by the presence of the roll jet, as previously stated. Owing to the geometry of the model, there is sufficient pressure relief to the left of the roll jet that this structure does not interact with the model surface on that side.

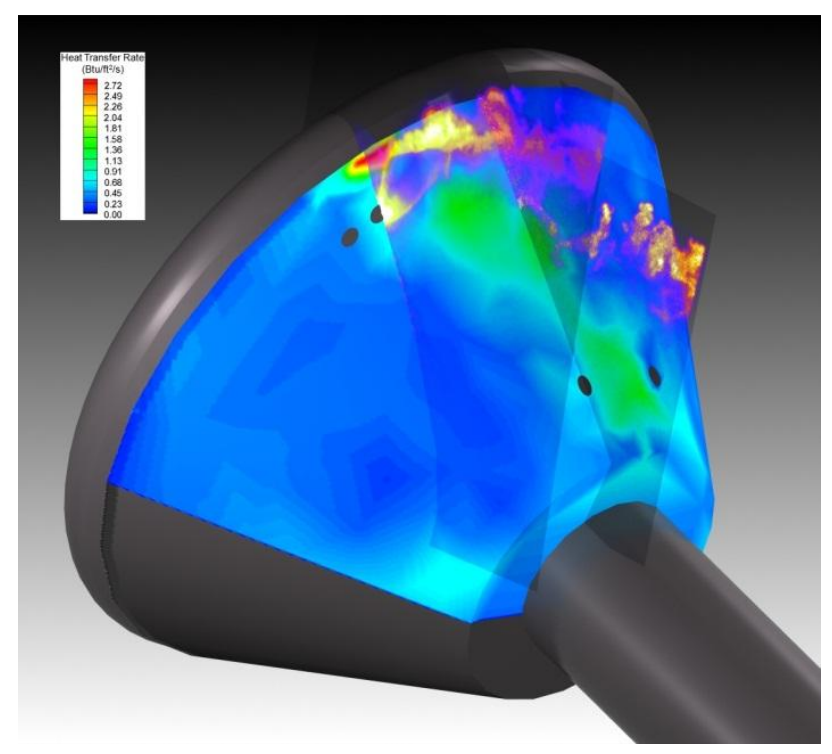

Figure 23: ViDI renderings of the capsule model at $18^{\circ} \mathrm{AoA}$ with NO PLIF visualization at two planes (from two separate runs) of an RCS roll jet pair issuing into a Mach 8 flowfield. Heat transfer data $\left(\mathrm{Btu} / \mathrm{ft}^{2} / \mathrm{s}\right)$ collected by a network of thin film sensors for this condition is displayed on the surface of the model. 
Simultaneous heat transfer measurements and PLIF flow visualization are shown in Figure 24 for the cases of a (a) single pitch down RCS jet and (b) dual pitch down jets firing from a capsule model at an $18^{\circ}$ angle of attack in a Mach 8 free-stream flow. In the single-jet case, the jet seems to have a minimal impact on the heat transfer at the nozzle exit. However, there is a large amount of heating upstream of the nozzle exit that seems to correspond with the high concentration of jet fluid in the wake region adjacent to the capsule afterbody. This concentrated heating is more intense than the similar area seen in Figure 22, with a peak heat transfer rate of $2.68 \mathrm{Btu} / \mathrm{ft}^{2} / \mathrm{s}\left(30.43 \mathrm{~kW} / \mathrm{m}^{2}\right)$. It may be that the recirculated pitch jet flow is interacting with the oncoming high stagnation temperature flow and a way that forces the flow to attach to the capsule afterbody and heat the surface. Previous experimental results and computer simulations revealed that heating upstream of pitch down jets should be expected. ${ }^{3}$ In the dual pitch jet case, the upstream heating is less intense with the heat transfer rate peaking at $1.55 \mathrm{Btu} / \mathrm{ft}^{2} / \mathrm{s}\left(17.60 \mathrm{~kW} / \mathrm{m}^{2}\right)$. The heating footprint is also approximately symmetrical about the centerline of the capsule model. Additionally, there is an area of relatively high heat transfer located at the pitch down nozzle exit to the right of the laser sheet. At this location there is a heat transfer spike with recorded heating rates as high as $9.72 \mathrm{Btu} / \mathrm{ft}^{2} / \mathrm{s}\left(110.38 \mathrm{~kW} / \mathrm{m}^{2}\right)$. It is difficult to discard this as an anomaly because relatively high heat transfer rates were recorded by multiple sensors in this area. Perhaps the two jets interact in such a way as to cause a shock or other flow structure to impinge on the surface of the model, resulting in a high heating footprint. It is also interesting that the upstream heating footprint is less intense in the dual jet case than the single jet case. This again may be a result of interactions between the two jets, where in this instance the interference prevents the recirculated flow from impinging on the model afterbody in the same manner as in the single jet case. Another possibility is that the same amount of recirculated flow has been entrained in the wake region but owing to the symmetry of the flow the heating footprint has been diffused over a larger area of the capsule afterbody.

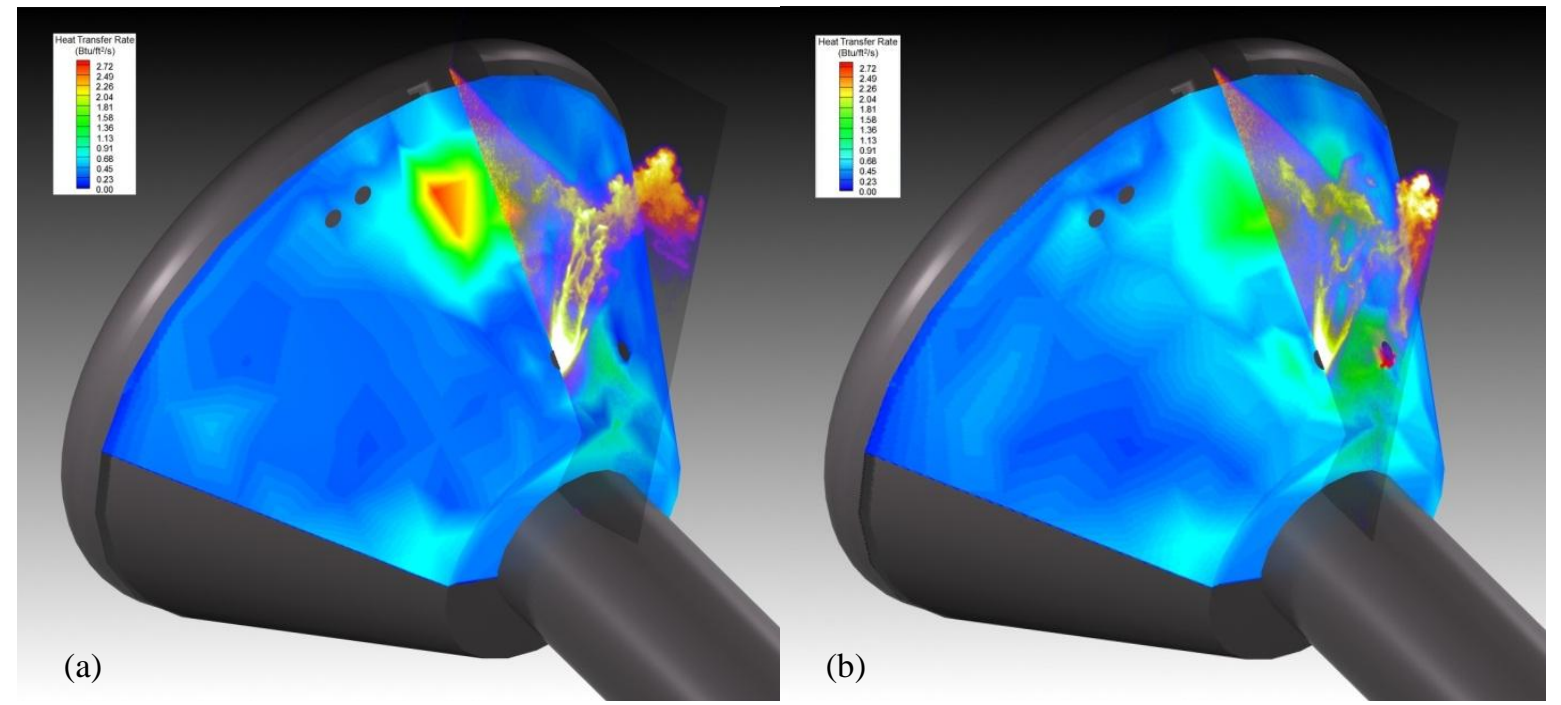

Figure 24: ViDI renderings of the capsule model at $18^{\circ}$ AoA with NO PLIF visualization of (a) 878 psia $\mathrm{RCS}$ pitch down jet and (b) 888 psia RCS pitch down jet pair issuing into a Mach 8 flowfield. Heat transfer data $\left(\mathrm{Btu} / \mathrm{ft}^{2} / \mathrm{s}\right)$ collected simultaneously by a network of thin film sensors is displayed on the surface of the model.

Figure 25 compares ViDI renderings of the capsule model at (a) $18^{\circ}$ angle of attack and (b) $22^{\circ}$ angle of attack with NO PLIF visualization of dual pitch down jets exhausting into a 0.1 psia Mach 8 flowfield. Image (a) is the same as Figure 24(b) but is included in this figure to aid in the comparison of the two images. The images are extremely similar qualitatively with almost the same heating footprint. Once again it appears that the $4^{\circ}$ change in angle of attack had little impact on the flowfield. Also, it is worth noting that the area of high (red on the color table) heat transfer upstream of the pitch jet seen in Figure 24(a) is not present in either image below. It is interesting that the addition of the second pitch jet appears to reduce the heating augmentation at that location. In both cases the heat transfer rate spikes and reaches a maximum at the pitch jet to the right of the model centerline. Again, it is difficult to determine the cause of this heating spike but it is most likely the result of some interaction between the two jets. 


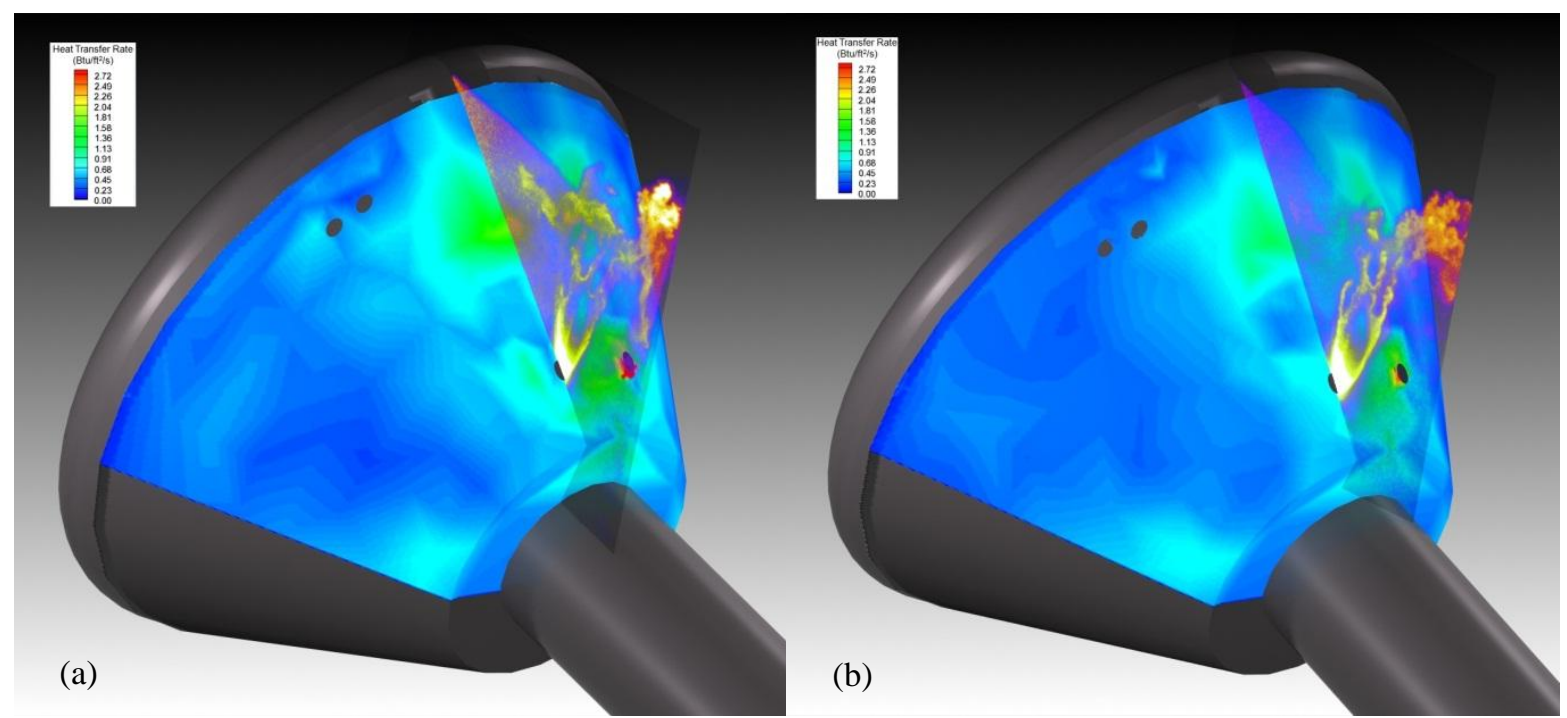

Figure 25: ViDI renderings of the capsule model at (a) $18^{\circ} \mathrm{AoA}$ and (b) $22^{\circ} \mathrm{AoA}$ with NO PLIF visualization of an RCS pitch down jet pair issuing into a 0.1 psia Mach 8 flowfield. Heat transfer data $\left(\mathrm{Btu}^{\mathrm{f}} / \mathrm{ft}^{2} / \mathrm{s}\right)$ collected simultaneously by a network of thin film sensors is displayed on the surface of the model.

In Figure 26 an NO PLIF visualization of an RCS pitch down jet firing in tandem with an RCS roll jet pair is shown for the $22^{\circ}$ angle of attack case with heat transfer rate contours plotted on the surface of the capsule model. In this image, elements of the heating footprints from the roll jet only and pitch jet only cases can both be seen. First, there is an area of relatively high heating near the lip of the leeward shoulder, which is the result of the pitch jet. Additionally, the path of the vortex created by the roll jet can be seen travelling down the backshell. The area of relatively high heating between the pitch jets can be seen, as well. This feature was seen in both the roll and pitch jet runs previously discussed. Lastly, the footprint upstream of the pitch jet that was seen clearly in Figure 24 and Figure 25 appears to have merged with the heating footprint left by the roll jet interaction. The fact that elements from the roll jet only and pitch jet only cases appear was to be expected, however, it is interesting that the combination of the jets has appeared to decrease the heat transfer rate on the backshell and eliminate the heating peaks exhibited in those cases. The peak heating value in this case is lower than the peak value for a dual roll jet and for a single pitch jet. Also, the mean heating value was the lowest mean heat transfer rate for any of the RCS test cases. 


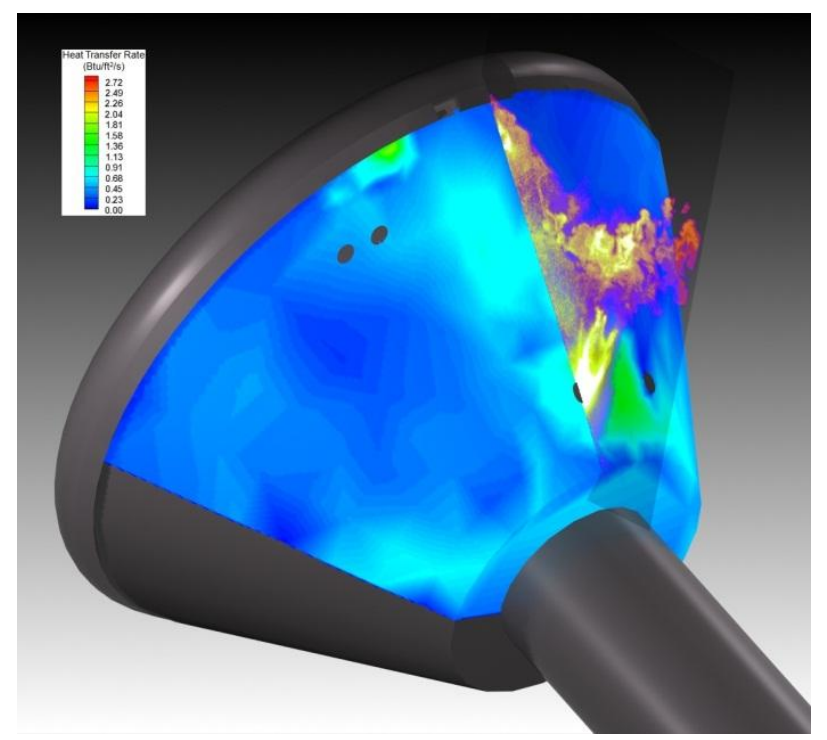

Figure 26: ViDI rendering of the capsule model at $22^{\circ} \mathrm{AoA}$ with NO PLIF visualization of a 368 psia RCS pitch down jet and 0.1 psia RCS roll jet pair issuing into a Mach 8 flowfield. Heat transfer data $\left(\mathrm{Btu} / \mathrm{ft}^{2} / \mathrm{s}\right)$ collected simultaneously by a network of thin film sensors is displayed on the surface of the model.

\section{Conclusion}

NO PLIF has been used to visualize RCS roll and pitch down jets on a capsule reentry vehicle at $18^{\circ}$ and $22^{\circ}$ angles of attack in the CUBRC LENS-I reflected shock tunnel facility. These tests have demonstrated that PLIF imaging of RCS jets in an impulse facility can yield insight into the behavior of the flow. The NO PLIF flow visualization was complemented by Schlieren imaging as well as heat transfer measurements collected by a network of thin film sensors on the surface of the model. At the baseline condition of a Mach 8 freestream and $\operatorname{Re}_{\mathrm{D}}=2.2 \mathrm{x}$ $10^{6}$, the shear layer was laminar with no RCS jets and with pitch down jets firing. It was also shown that the shear layer is relatively steady near the lip of the model but becomes increasingly unstable further downstream. As expected, higher Reynolds number flows showed more turbulent flow structures and shear layers. For the case with roll jets firing, there was a significant interaction between the jets and the shear layer, but it was unclear whether the shear layer was turbulent or simply unsteady. It was also demonstrated that by using low levels of $\mathrm{O}_{2}$ in a $\mathrm{N}_{2}$ test gas and testing at higher enthalpy conditions, NO PLIF images could be collected by taking advantage of the naturally-occurring NO gas in the flow. Using this method, the shear layer, lip shock, and expansion fan generated by the capsule model were visualized. The shear layer was also imaged at low-enthalpy, jet-off conditions by seeding NO gas through a porous cylinder directly into the flow. The visualization of the shear layer through porous cylinder seeding, imaging of naturally-occurring NO, and Schlieren imaging compared favorably. Lastly, the heat transfer measurements on the surface of the model were compared with NO PLIF images to better understand the fluid physics. Roll jet fluid was not observed to correlate with the heating footprint observed near the jets. Rather, it is proposed that a secondary structure, such as a horseshoe vortex, is forming around the RCS roll jet and heating the surface of the model. Additionally, it was observed that fluid from the pitch-down jet interacts with the oncoming flow in a way that generates heating on the backshell surface upstream of the nozzle exit. Another interesting result was that the case with pitch jets and roll jets firing exhibited the lowest heating augmentation of any of the tests with RCS jets firing. These results will be compared with CFD simulations to result in increased understating of how the RCS jets will perform during flight.

\section{Acknowledgements}

We wish to acknowledge the contribution to this project from the CUBRC LENS-I shock tunnel technicians and engineers. This work was supported in part by NASA NSTRF Training Grant NNX11AN55H. The work was also supported by NASA's Orion CEV Aeroscience Program (CAP) from NASA Langley Research Center and NASA Johnson Space Center. 


\section{References}

${ }^{1}$ F. Sietzen Jr., "From Mercury to CEV: Space Capsules Reemerge,” Aerospace America, p. 26-33, Feb., 2005.

${ }^{2}$ Anon., "NASA's Exploration Systems Architecture Study: Final Report," NASA TM-2005-214062, Nov., 2005.

${ }^{3}$ A.A. Dyakonov, G.M. Buck, and A.D. Decaro, "Analysis of Aeroheating Augmentation due to Reaction Control System Jets on Orion Crew Exploration Vehicle," AIAA Paper 2009-3844, 41st AIAA Thermophysics Conference San Antonio, Texas, Jun. 22-25, 2009.

${ }^{4}$ C.A. Vaughn, "Apollo Reaction Control Systems," AIAA Paper 68-566, AIAA 4th Propulsion Joint Specialist Conference, Cleveland, Ohio, Jun. 10-14, 1968.

${ }^{5}$ M.A. Kane, “Orion Touchdown Heading Control," NASA JSC-CN-20353, Apr., 2010.

${ }^{6}$ L.A. Cassel, "Applying Jet Interaction Technology," Journal of Spacecraft and Rockets, Vol. 40, No. 4, Jul.Aug. 2003, pp. 524-537.

7 J.A. Inman, "Fluorescence Imaging Study of Free and Impinging Supersonic Jets: Jet Structure and Turbulent Transition," Ph.D. Thesis, The College of William and Mary, Williamsburg, Virginia, 2007.

${ }^{8}$ R.A. Jones and J.L. Hunt, "Effects of Cavities, Protuberances, and Reaction-Control Jets on Heat Transfer to the Apollo Command Module," NASAA TM X-1063, Mar. 1965.

${ }^{9}$ G.M. Buck, A.N. Watkins, P.M. Danehy, J.A. Inman, D.W. Aldefer, and A.A. Dyakonov, "Experimental Measurement of RCS Jet Interaction Effects on a Capsule Entry Vehicle," AIAA Paper 2008-1229, 46th AIAA Aerospace Sciences Meeting and Exhibit, Reno, Nevada, Jan. 7-10, 2008.

${ }^{10}$ M.J. Wright, F.S. Milos, and P. Tran, "Afterbody Aeroheating Flight Data for Planetary Probe Thermal Protection System Design,” Journal of Spacecraft and Rockets, Vol. 43, No. 5, Sep.-Oct. 2006, pp. 929-943.

${ }^{11}$ J.J. Jones and J.A. Moore, "Shock-Tunnel Heat-Transfer Investigation on the Afterbody of an Apollo-Type Configuration at Angles of Attack up to 45," NASA TM-X-1042, Dec., 1964.

${ }^{12}$ Anon., "Project Mercury Preliminary Flight Test Results of the "Big Joe", Mercury R and D Capsule," NASA TM-X-73017, Oct., 1959.

${ }^{13}$ E.W. Stephens, "Afterbody Heating Data Obtained from an Atlas-Boosted Mercury Configuration in a Free Body Reentry,” NASA TM-X-493, Aug., 1961.

${ }^{14}$ A. N. Watkins, G. M. Buck, B. D. Leighty, and W. B. Lipford, "Using Pressure- and Temperature-Sensitive Paint on the Aftbody of a Capsule Vehicle," AIAA Journal Vol. 47, No. 4, Apr. 2009, pp. 821-829.

${ }^{15}$ C. B. Ivey, P. M. Danehy, B. F. Bathel, A. A. Dyakonov, J. A. Inman, and S. B. Jones, "Comparison of PLIF and CFD Results for the Orion CEV RCS Jets" AIAA Paper 2011-713, 49th AIAA Aerospace Sciences Meeting, Fluid Dynamics TC, Orlando, Florida, Jan. 2011.

${ }^{16}$ C.T. Johansen, L.A. Novak, B.F. Bathel, S.W. Ashcraft, and P.M. Danehy, "Comparison of MSL RCS Jet Computations with Flow Visualization and Velocimetry," AIAA Paper 2012-0594, 50 ${ }^{\text {th }}$ AIAA Aerospace Sciences Meeting and Exhibit, Nashville, Tennessee, Jan. 9-12, 2012.

${ }^{17}$ J.A. Inman, P.M. Danehy, D.W. Alderfer, G.M. Buck, and A. McCrea, "Planar Fluorescence Imaging and Three Dimensional Reconstructions of Capsule Reaction-Control-Systems Jets," AIAA Journal Vol. 47, No. 4, Apr. 2009.

${ }^{18}$ J. A.(Wilkes) Inman, P. M. Danehy, D. W. Alderfer, and G. M. Buck, A. McCrea, and R. J. Schwartz, "PLIF Imaging of Capsule RCS Jets and Simulated Forebody Ablation" AIAA Paper 2008-0248, 46th AIAA Aerospace Sciences Meeting and Exhibit, Reno, Nevada, Jan. 7-10, 2008.

${ }^{19}$ P. M. Danehy, J. A. Wilkes, D. W. Alderfer, S. B. Jones, A. W. Robbins, D. P. Patry and R. J. Schwartz, "Planar laser-induced fluorescence (PLIF) investigation of hypersonic flowfields in a Mach 10 wind tunnel" AIAA Paper 2006-3442, AIAA AMT-GT Technology Conference, San Francisco, Jun., 2006.

${ }^{20}$ N. Jiang, J. Bruzzese, R. Patton, J. Sutton, W. Lempert, J.D. Miller, T.R. Meyer, R. Parker, T. Wadham, M. Holden, P.M. Danehy, "NO PLIF Imaging in the CUBRC 48 Inch Shock Tunnel" AIAA Paper 2011-0928, 49th AIAA Aerospace Sciences Meeting, Orlando, Florida, Jan. 4-7, 2011.

${ }^{21}$ P. C. Palma, S. G. Mallinson, S. B. O’Byrne, P. M. Danehy, and R. Hillier, "Temperature measurements in a hypersonic boundary layer using planar laser-induced fluorescence," AIAA Journal, Vol. 38, No. 9, 2000, pp. 17691772 .

${ }^{22}$ R. Hruschka, S. O’Byrne, and H. Kleine, “Two-component Doppler-shift fluorescence velocimetry applied to a generic planetary entry probe model," Experiments in Fluids, Vol. 48, 2010, pp. 1109-1120.

${ }^{23}$ W. M. Ruyten, M. S. Smith, L. L. Price, and W. D. Williams, "Three-line fluorescence thermometry of optically thick shock-tunnel flow," Applied Optics, Vol. 37, No. 12, Apr. 1988, pp. 2334-2339. 
${ }^{24}$ W. H. Beck, M. Wollenhaupt, M. Rosenhauer, T. Mueller, and J. Jourdan, "Status of the development and implementation of optical spectroscopic techniques on the DLR high enthalpy shock tunnel HEG," AIAA Paper 962221, 19th AIAA Advanced Measurement and Ground Testing Technology Conference, New Orleans, LA, Jun. 1996.

${ }^{25}$ P. M. Danehy, J. A. Inman, G. J. Brauckmann, D. W. Alderfer, S. B. Jones, and D. P. Patry, "Visualization of a Capsule Entry Vehicle Reaction-Control System (RCS) Thruster," Journal of Spacecraft and Rockets, Vol. 46, No. 1, Jan.-Feb. 2009, pp. 93-102.

${ }^{26}$ B. Shirinzadeh, R.J. Balla, and M.E. Hillard, "Rayleigh scattering measurements in supersonic facilities," AIAA Paper 96-2187, 19th AIAA Advanced Measurement and Ground Testing Technology Conference, New Orleans, LA, Jun. 1996.

27 M. S. Holden and R.A. Parker, "LENS Hypervelocity Tunnels and Application to Vehicle Testing at Duplicated Flight Conditions." F.K. Lu and D.E. Marren. Advanced Hypersonic Test Facilities. Vol. 189. Reston, VA: AIAA, 2002. 73-110. Print.

${ }^{28}$ J. A. Wilkes, D. W. Alderfer, S. B. Jones, and P. M. Danehy, "Portable Fluorescence Imaging System for Hypersonic Flow Facilities," JANNAF Interagency Propulsion Committee Meeting, Colorado Springs, Colorado, Dec. 2003.

${ }^{29}$ P. M. Danehy, J. A. Inman, D. W. Alderfer, G. M. Buck, B. Bathel, "Visualization of flowfield modification by RCS jets on a capsule entry vehicle", AIAA Paper 2008-1231, 46th AIAA Aerospace Sciences Meeting and Exhibit, Reno, Nevada, Jan. 7-10, 2008.

${ }^{30}$ P. M. Danehy, D. W. Alderfer, J. A. Inman, K. T. Berger, G. M. Buck, and R. J. Schwartz, "Fluorescence Imaging and Streamline Visualization of Hypersonic Flow Over Rapid Prototype Wind-Tunnel Models" Proc. IMechE, Part G: J. Aerospace Engineering, 222 (G5), pp. 637-651, 2008.

${ }^{31}$ D. W. Alderfer, P. M. Danehy, J. A. Wilkes Inman, K. T. Berger, G. M. Buck, and R. J. Schwartz, "Fluorescence Visualization of Hypersonic Flow Over Rapid Prototype Wind-Tunnel Models" AIAA Paper 20071063, 45th AIAA Aerospace Sciences Meeting and Exhibit, Reno, Nevada, Jan. 8-11, 2007.

${ }^{32}$ R. J. Schwartz, "ViDI: Virtual Diagnostics Interface Volume 1-The Future of Wind Tunnel Testing" Contractor Report NASA/CR-2003-212667, Dec. 2003.

${ }^{33}$ Autodesk 3ds Max Product Information, Autodesk Inc., http://usa.autodesk.com/adsk/servlet/index?id=5659302\&siteID=123112, viewed Jan 2, 2006. 